\title{
Praileaitz I haitzuloa (Deba, Gipuzkoa, Euskal Herria). Deskribapena. Testuinguru geografikoa eta arkeologikoa
}

\author{
Praileaitz I Cave (Deba, Gipuzkoa, Basque Country). Description. \\ Geographical and archaeological context \\ Cueva de Praileaitz I (Deba, Gipuzkoa, Euskal Herria). Descripción. \\ Contexto geográfico y arqueológico
}

GAKO-HITZAK: Euskal Herria, Praileaitz I, Testuingurua, Indusketa arkeologikoa.

KEYWORDS: Basque Country, Praileaitz I, Context, Excavation.

PALABRAS CLAVE: Euskal Herria, Praileaitz I, Contexto, Excavación arqueológica.

Sonia SAN JOSE(1), Xabier PEÑALVER(2), Jose Antonio MUJIKA-ALUSTIZA ${ }^{(3)}$

\section{LABURPENA}

Praileaitz I haitzuloa (Deba) Deba ibaiaren meandro baten gainean dago, itsas mailatik $65 \mathrm{~m}$ gora, kostaldetik hurre, eta okupazio paleolitikoa duten kobazulo ugariko inguru batean. Artikulu honetan koba eta bertan egindako indusketa arkeologikoak azaltzen dira. Izan ere, aztarnategiko hainbat lekutan indusketa arkeologikoa egin zen 2000. eta 2009. urteen artean, eta zenbait maila antzeman ziren: Gravette, Solutre, Behe-Madeleine, Goi-Azken Madeleine eta Epipaleolito aldiak; horrez gain, barruan labar-pinturak aurkitu ziren. Era berean, inguruneko haitzulo garrantzitsuen eta bertan egindako lan arkeologikoen deskripzioa egiten da.

\section{ABSTRACT}

Praileaitz I (Deba, Gipuzkoa) is a cave placed on a bend of the Deba River, at $65 \mathrm{~m}$ above sea level, near the coast, surrounded by an area where cavities with Palaeolithic remains are abundant. This cave and the excavations in it will be the main subject of this article. Between 2000 and 2009, Praileaitz I has been excavated in several areas and Gravettian, Solutrean, Lower and Upper-Final Magdalenian and Epipalaeolithic levels and, also, rock art, have been detected and studied. We shall describe briefly the most interesting caves of the surrounding area and the archaeological works developed in them.

\section{RESUMEN}

La cueva de Praileaitz I (Deba) se abre sobre uno de los meandros del río Deba a 65 m s.n.m., cerca de la costa, y en un contexto de abundancia de cavidades con ocupaciones paleolíticas. En este artículo se presenta la cavidad y las excavaciones arqueológicas realizadas en la misma. En el yacimiento se ha intervenido entre el 2000 y el 2009 en diferentes espacios y se han detectado niveles correspondientes al Gravetiense, Solutrense, Magdaleniense Inferior, Magdaleniense Superior-Final y Epipaleolítico, además de haberse hallado pinturas rupestres. Así mismo, se hace una breve descripción de las cuevas más relevantes del entorno y de los trabajos arqueológicos realizados en ellas.

\section{1.- SARRERA}

Debabarrenan duela hamarkada asko ezagutzen ziren aztarnategi arkeologikoa zuten haitzulo ugari, eta, zegoeneko, XX. mende hasieran indusi zituzten haietako batzuk.

Zonalde honetan, Deba ibaiak sortzen dituen meandroen inguruan, kareharrizko mendi ugari daude egokiegokiak giza-taldeak bizitzen jartzeko, Paleolitoan batez ere.

Hamaika haitzulo aztarnategidun katalogatu diren inguru honetan altxatzen da Praileaitz mendia, inguru guztian Deba ibaiaren ibilgua duela.
Hamarkada dezente dira harrobi batek ustiatzen duela Praileaitz mendia (1. ird.), eta, gaur egun, zerrenda periferiko estu bat baino ez da geratzen, non haitzulo ugari dauden, horien artean Praileaitz I. la-ia mendi osoa desegin eta desagerrarazi dute, eta horrekin batera hainbat haitzulo, batzuk ezezagunak, beste batzuk ezagunak, adibidez Praileaitz II.

Hain zuzen ere, suntsipenaren mehatxupean zegoelako hasi zen Praileaitz I haitzuloaren indusketa. Lanak 2000. urtean hasi ziren eta oraindik jarraitzen dute (2. ird.) eta barruan labar-pinturak aurkitzeak eragotzi du aztar-

\footnotetext{
(1) Historiaurreko Arkeologia Saila. Aranzadi Zientzi Elkartea. Zorroagagaina 11. 20014 DONOSTIA. ssanjose@aranzadi.eus

(2) Historiaurreko Arkeologia Saila. Aranzadi Zientzi Elkartea.

(3) Letren Fakultatea (Euskal Herriko Unibertsitatea).
} 


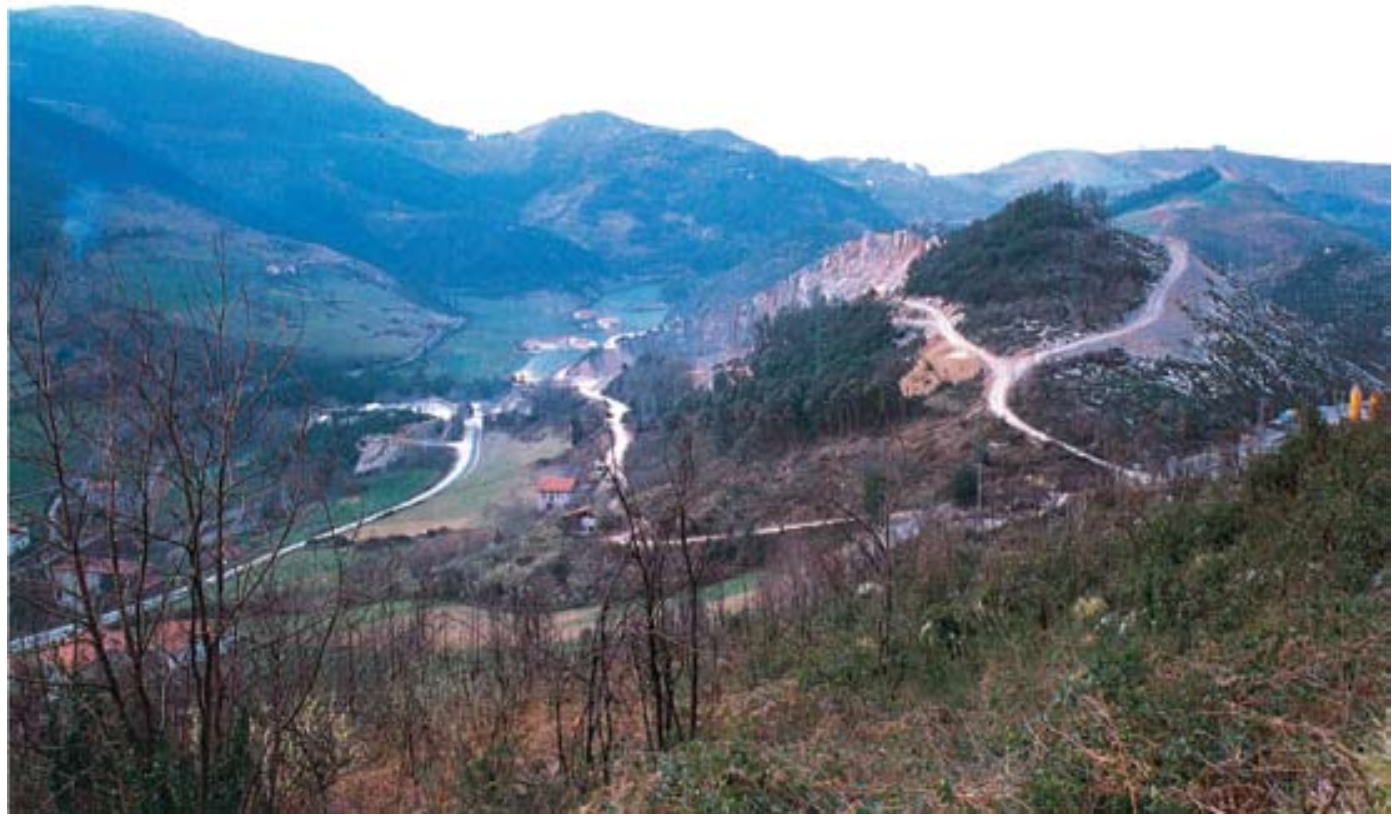

1. ird. Praileaitz mendia 80. hamarkadaren bukaeran (LARRAÑAGA 1991: 63). / Mount Praileaitz at the end of the eighties (LARRAÑAGA 1991: 63).

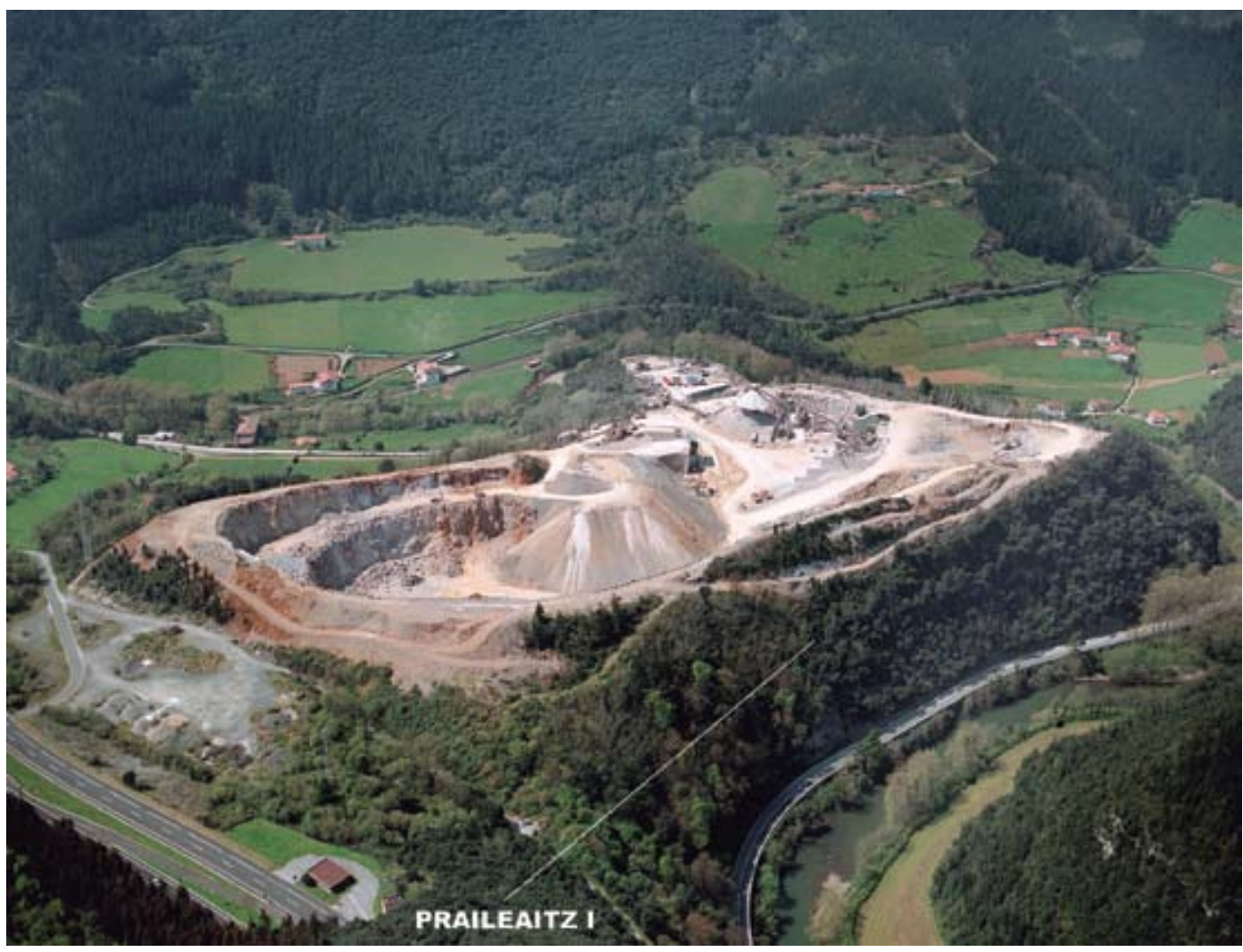

2. ird. Praileaitz mendia gaur egun (PAISAJES). /Mount Praileaitz nowadays (PAISAJES). 
nategi hau hondatzea, nahiz eta inguru hurbila desagerrarazten ari den, egunak joan egunak etorri, agregakinak erauzteko (PEÑALVER, SAN JOSE, 2008 eta 2009).

Bai haitzulorako sarrera berria eta sedimentuz edo jalkinez betetako galeria berriak orain dela gutxi aurkitzeak, bai Erdi Paleolitoari lotutako maila agertzeak ematen diote leku honi are garrantzi eta interes handiagoa ikerkuntzak jarrai dezan.

\section{2.- PRAILEAITZ I HAITZULOA}

Praileaitz I ${ }^{1}$ haitzuloa haitzuloa landaredi itxiko mendi -hegal handi batean dago, Deba ibaiaren eskuineko ertzean, ibaiaren ibilgutik 65 m gora gutxi gorabehera; ibaia bertatik pasatzen da meandroak osatuz kareharrizko mendi-hegal malkartsuen artean. Kobazulo honen ahoa ipar-ekialderantz begira dago (4. ird.) eta ezagutzen den luzera 80 m gutxi gorabeherakoa da. Tamaina txikiagoko beste haitzulo batzuk daude prospekzioak egiteko ezin zailagoa den mendi-hegal horretan.

Debako herrigunetik haitzulora iristeko, beharrezkoa da beharrezkoa da hartzea Artzabal auzoko zentral elektriko txikitik ateratzen den zementuzko bidea, Elgoibarko noranzkoan. Bide hori Deba ibilguarekiko paralelo samar doa, baina gorago, eta jarraitu behar da harik eta ia-ia Bilbo-Behobia autopistara eta Lasturreko errepidera iritsi arte. Zabaldegi ezin txikiago batetik (antzinako zabortegia) bidexka estu bat ateratzen da Praileaitz lera eramaten duena.

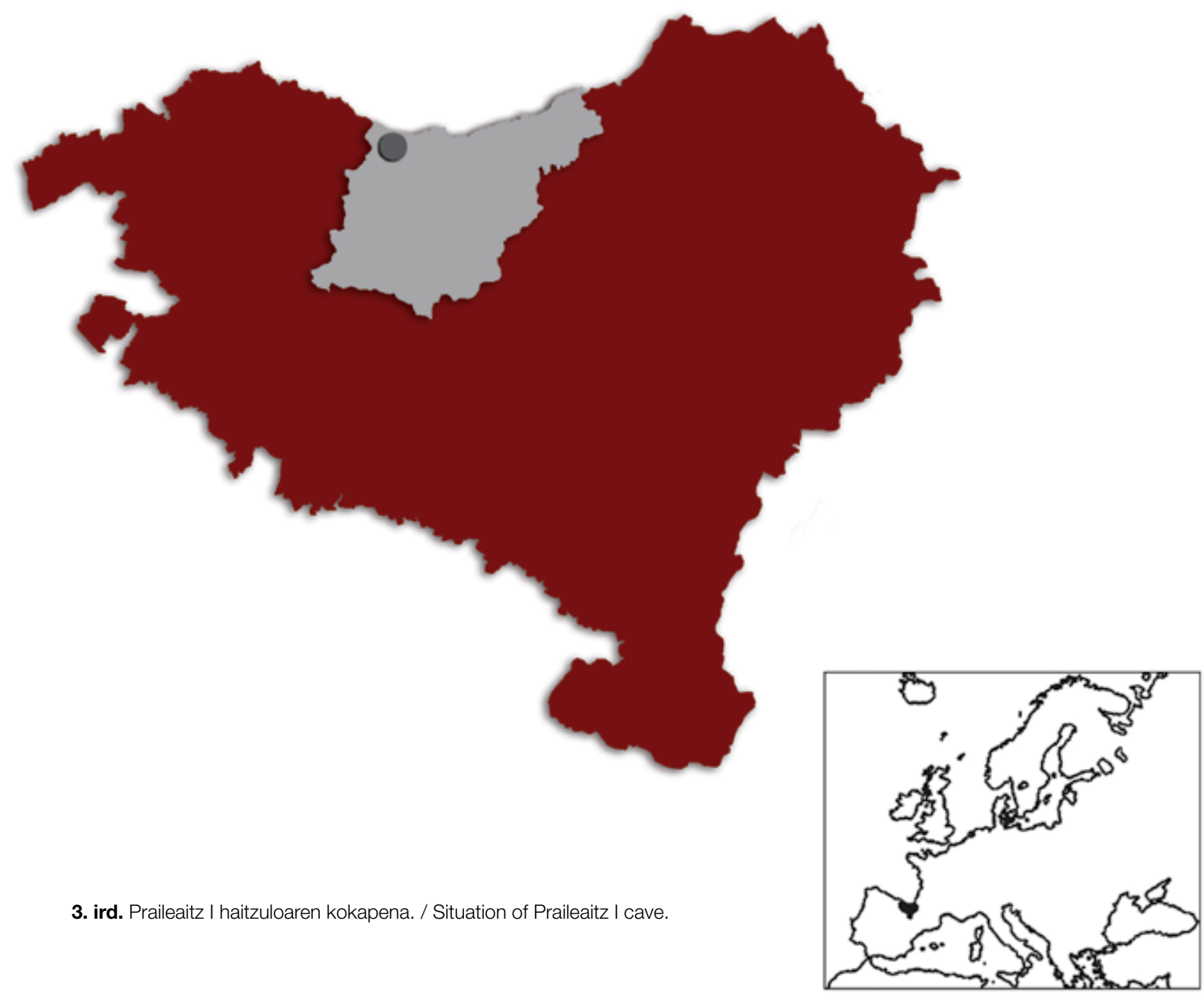

${ }^{1}$ 2006. urtera arte, haitzuloa Praile Haitz I izenez katalogatu zen. 
Haitzuloaren koordenadak (ED50, 30T) honakoak dira: X. 551.402; Y. 4.791.973; Z. 65 (3. ird.)

Kobazuloaren kanpoaldean, sarreraren ekialdean, babesleku txiki bat dago $5 \mathrm{~m}$ luze eta 3 eta $5 \mathrm{~m}$ zabal, zeinak gutxi gorabehera $25 \mathrm{~m}$-ko azalera (7. ird.) hartzen duen. Azalera horretatik $16 \mathrm{~m}^{2}$ indusi dira. Potentzia estratigrafiko emankorra 1,95 m-koa da, eta bertan antze- man dira giza-okupazioaren aztarna gutxi batzuk eta fauna ugariago, hainbat une kronologikokoak.

Haitzuloaren sarrerak itxura ia triangeluarra du (5. eta 6. ird.), gehienez ere $6 \mathrm{~m}$ garai eta oinarrian 2,50 zabal. Aurkikuntzaren garaian, ezkerreko hormatik erori eta pareko hormaren kontra zegoen bloke handi batek hartzen zuen sarreraren zati bat.

4. ird. Praileaitz I haitzuloaren plano orokorra (G. Studer, Tx. Ugalde -Felix Ugarte Elkartea-). / General plan of Praileaitz I cave (G. Studer, Tx. Ugalde -Felix Ugarte Elkartea-).
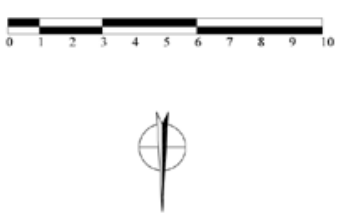

PRAILEAITZ I

(Deba)
BIGARREN BARNE-GELA

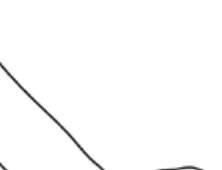

MARGOEN GELA

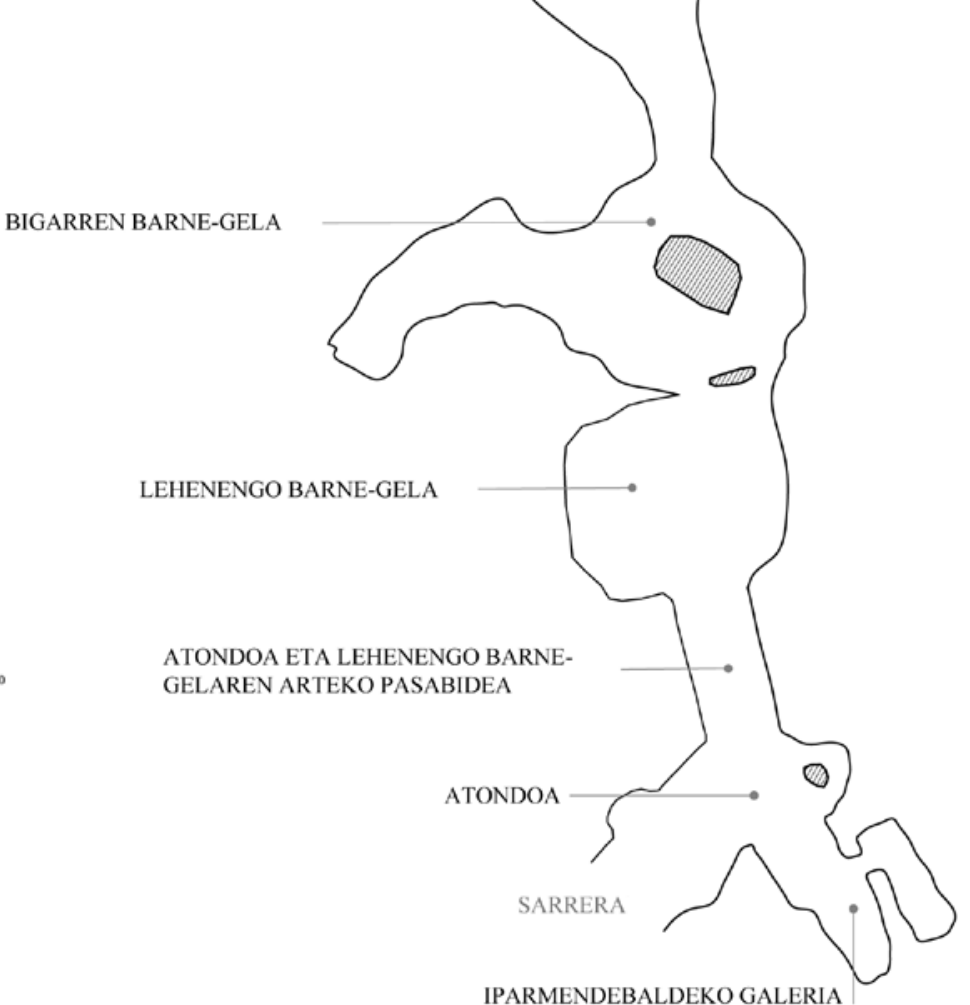




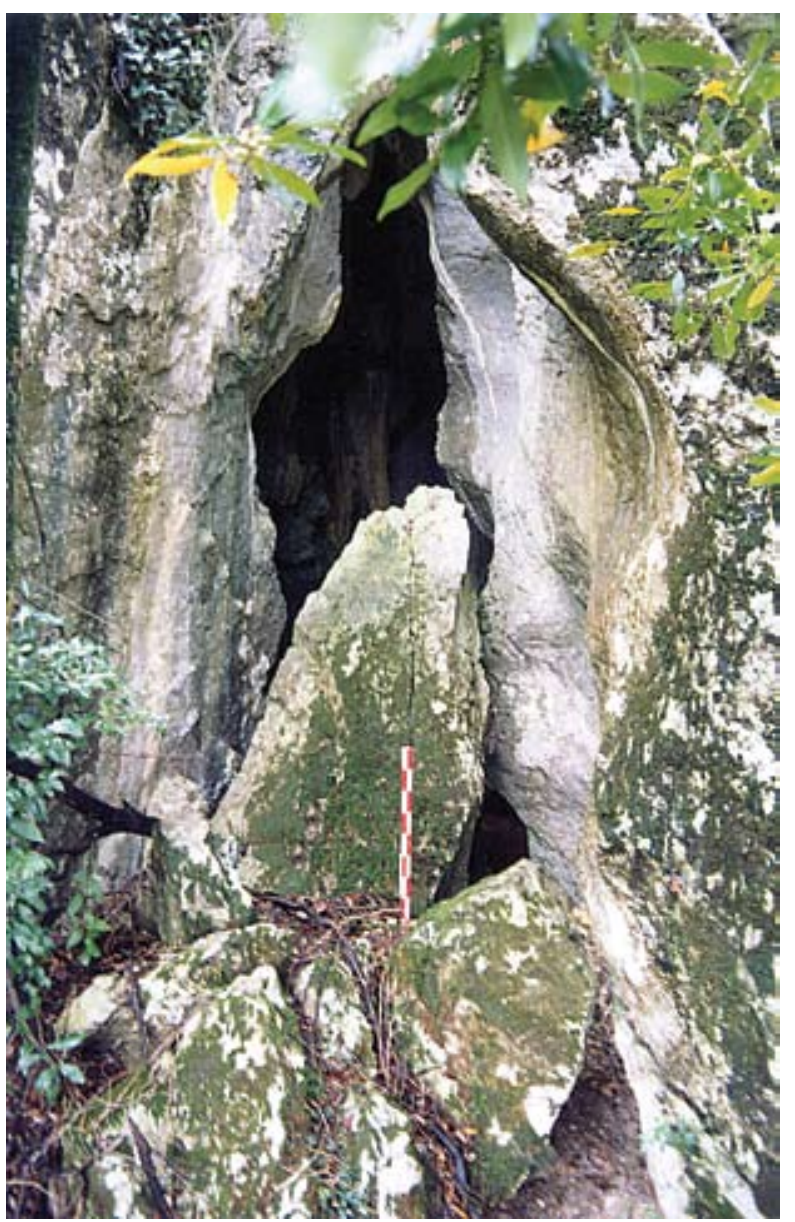

Sarrera hori igarota, $34 \mathrm{~m}^{2}-\mathrm{ko}$ atondo bat zabaltzen da (8. ird.), I-H norabidean $7 \mathrm{~m}$ eta E-M-an 5 m-ko gehieneko luzera duelarik. Erdiko guneak 10,40 m dauzka, non zulo txiki edo tximinia bat zabaltzen den, eta bertatik sartu da bertan dagoen sedimentuaren zati bat. Ekarpen natural horretaz gain, gune horrek -haitzuloko argitsuena- potentzia estratigrafiko handiena du, han antzeman baitira hainbat okupazio labur Epipaleolitotik Solutre aldira. Gela-

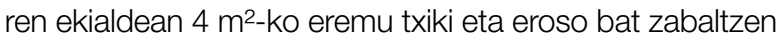
da. Gunearen sabaia 0,80 m altu baino ez da, eta atariaren gainontzeko zatitik kareharrizko hiru blokek banantzen dute. Horietako bat dimentsio handikoa eta sabaitik eroria da; beste biak, beren neurria dela-eta, beharbada lekualdatuta daude sektorea egokitzeko edo mugatzeko.

Haitzuloaren sarrerako bloke handi eroriak kenduta, HE hormaren haustura-planoan, jalkinez betetako zulo txiki bat agertzen da, zeina azalez azal indusi den. Atondo indusketa orokorra bukatuta (26. azala), zulo txiki horrek erakusten du ganga-formako itxura, eta oinplanoa ia erdizirkularra du, 2 m (HM-IE ardatza) eta 1,30 m-ko (HE-IM ardatza) neurriekin.

Atondotik bi galeria ateratzen dira: bata, IM-rantz 12 m2-ko azalerakoa, gaurkoz 5 m-ko luzera irisgarri, 1,5 eta 3,5 m arteko zabalera du; horren mendebaldean jalkinez

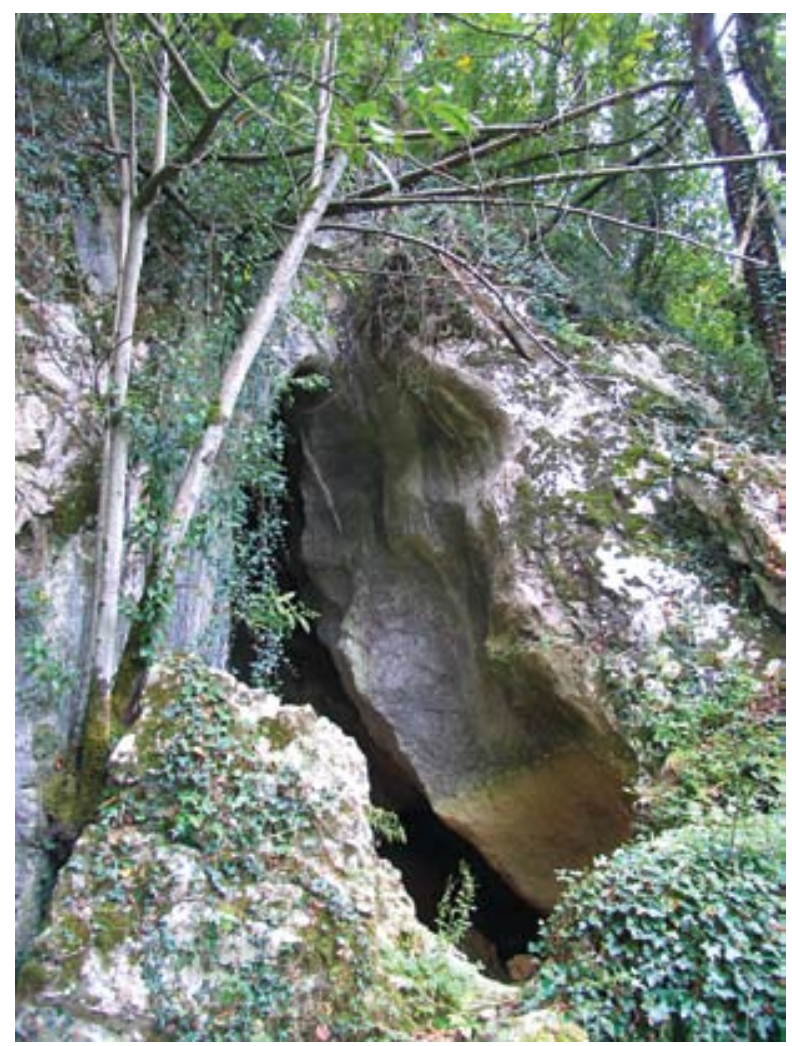

5.-6. ird. Haitzuloaren sarrera aurkikuntzaren unean (1983) (Munibe Taldea) eta indusketa-lanetan zehar. / The entrance to the cave at the moment of the discovery (1983) (Munibe Taldea) and along the excavation works.

betetako galeria bat ateratzen da non 4,5 m ibil daitekeen (9. ird.); bestea H-rantz zabaltzen da, eta haitzuloaren baruko espazioetarako pasabidea da.

Pasabide hori (10. ird.), hegoalderantz orientatua, atondoa estuen den lekutik abiatzen da, eta bertan sabaia jaisten da 1,30 m-raino. Galeria horren azalera 12 $\mathrm{m}^{2}$-koa da eta zabalera 2,80 eta 4,50 metroen artekoa. Arkeologia-lanak hasi zirenean, geruza estalagimitiko lodi handi batez estalia zegoen.

Gune estuago horren ondoren, lehen barne-gela zabaltzen da (11. ird.), gutxi gorabehera itxura zirkularrekoa, azalera 43 m²-koa, diametroa $7 \mathrm{~m}$-koa eta erdian gehienezko altuera 2 eta 2,25 m-en artekoa, non ozta-ozta sartzen den argi naturala. Esparru horretan indusitako potentzia estratigrafikoa atarikoa baino askoz txikiagoa da, baina bertan antzeman dira hainbat maila arkeologiko: Epipaleolitoa, Behe-Madaleine aldia eta Solutre aldia. Haitzuloko beste esparru batzuetan bezala, azalera hori zigilatuta zegoen geruza estalagmitiko batez, eta geruza horrek finkatzen zuen lurzoru horizontal-horizontala.

Bi aho txikiz (bakoitza $1 \mathrm{~m}$ zabal) osatutako pasabide estu batetik bigarren barne-gelara sartzen da (12. ird.). Bigarren horren hedadura $42 \mathrm{~m}^{2}$-koa da eta gehienezko altuera 1,57 m-koa gela guztiz estaltzen zuen geruza es- 


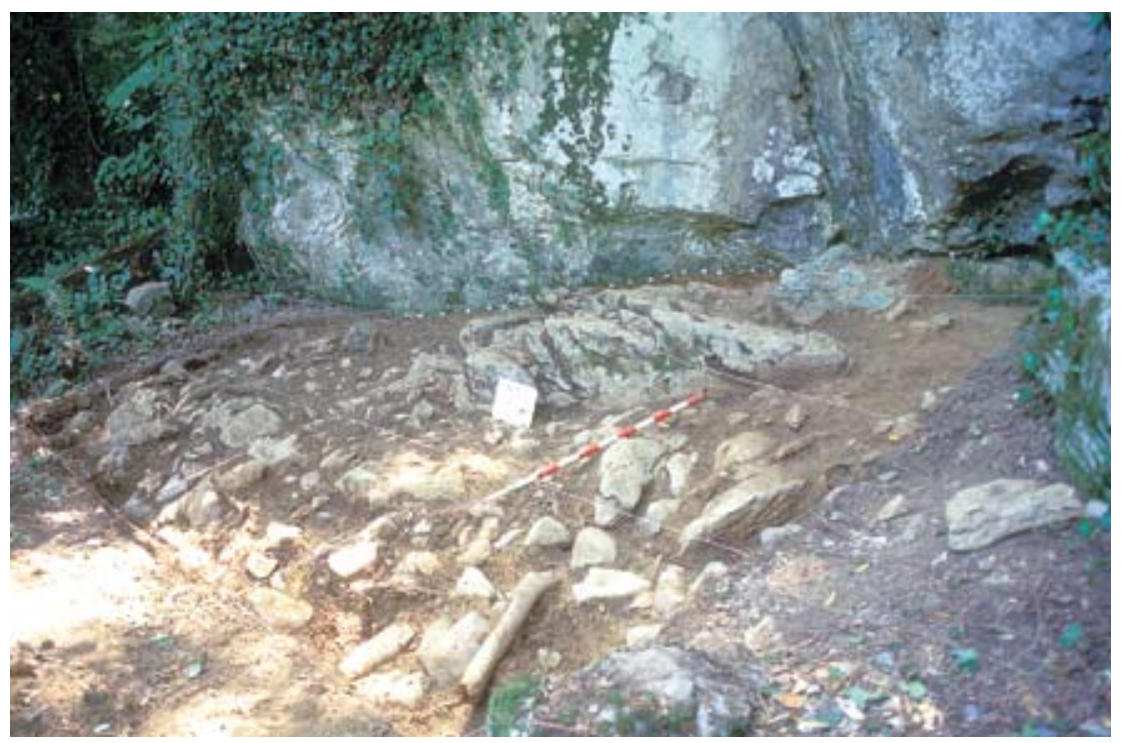

7-9. ird. Praileaitz l-eko landutako eremu ezberdinak. Goitik behera: 7. Kanpoko zonaldea. 8. Atondoaren ekialdeko txokoa. 9. Iparmendebaldeko galeria. / Excavation areas at Praileaitz I. From up to down: 7. Outside area. 8. East corner of the hall. 9. Northwest gallery.
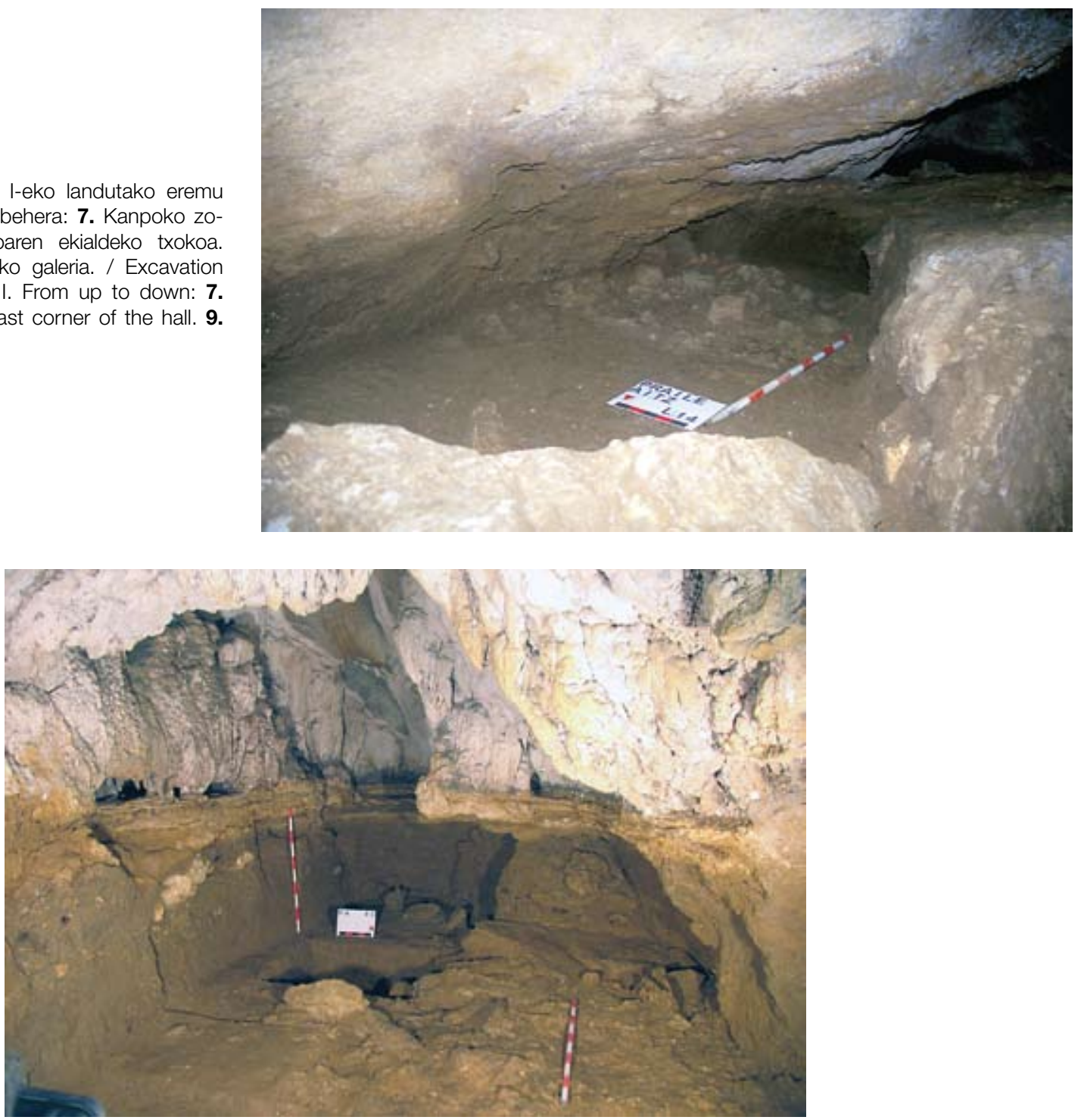
10-12. ird. Praileaitz l-eko landutako eremu ezberdinak. Goitik behera eta ezkerretik eskuinera: 10. Atondoa eta lehen barne-gelaren arteko pasabidea. 11. Lehen barne-gela. 12. Bigarren barne-gela. / Excavation areas at Praileaitz I. From up to down and from left to right: $\mathbf{1 0 .}$ Area leading from the vestibule to the first inner room. 11. First inner room. 12. Second inner room.
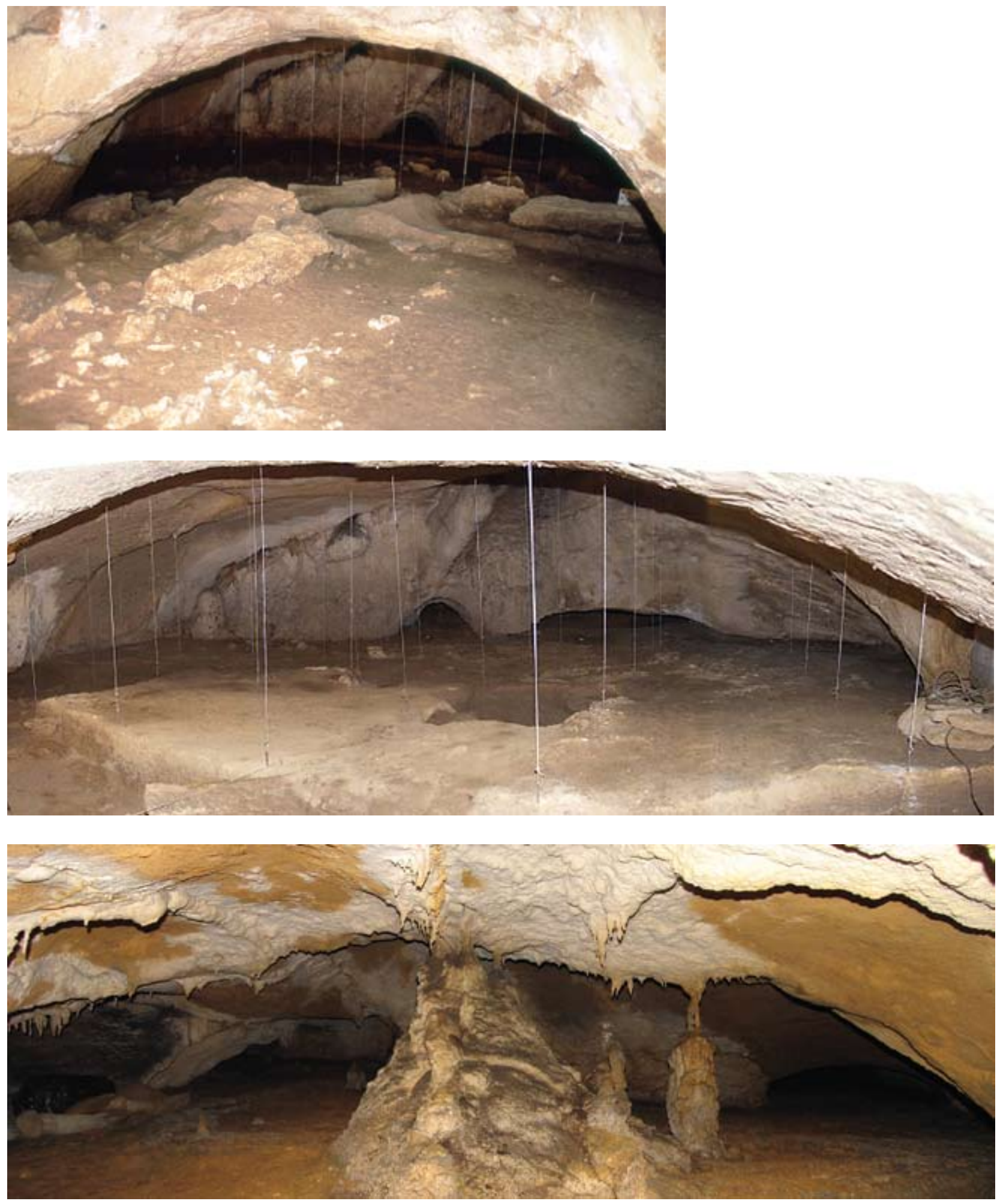


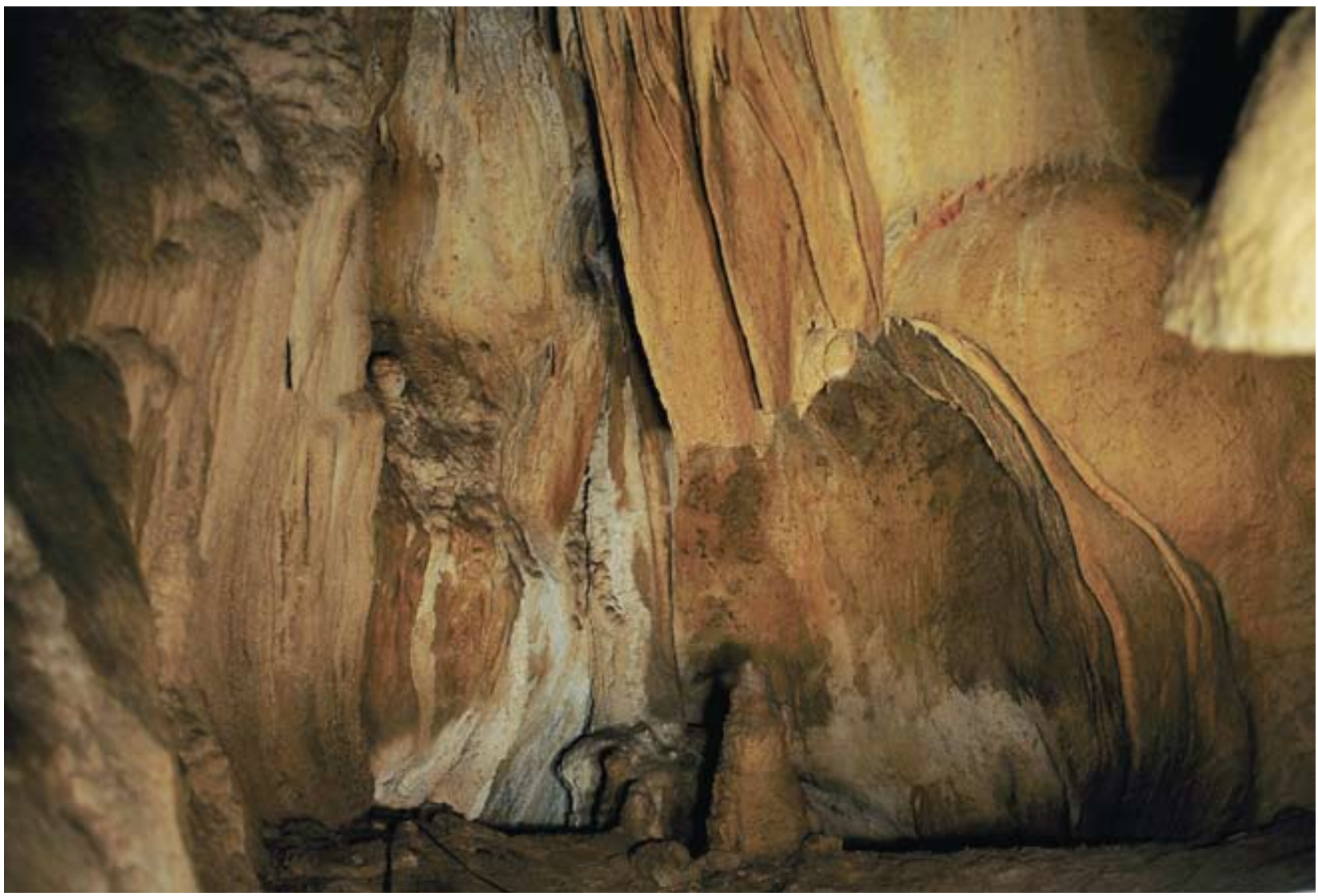

13. ird. Praileaitz l-eko margoen gela. / Paintings room at Praileaitz I.

talagmitikotik gora. Erdian bada zutabe estalagmitiko handi bat $4 \mathrm{~m}^{2}$-ko azalera hartzen duena eta ekialderantz, 7 $\mathrm{m}$ garapeneko galeria txiki bat, E-IE orientazioa duena.

Bigarren barne-gelatik aurrera haitzuloak jarraitzen du hainbat galeriaren bidez, ia denak geruza estalagmitiko batez estaliak; galeria horietan ez da esku-hartze arkeologikorik egin.

Lehenengo galeriak 13 m-ko luzera eta zabalera aldakorra du, baina bere garapeneko erdi-erdian $5 \mathrm{~m}$ zabal du. Jarraian, bi galeriatan adarkatzen da: bata, $15 \mathrm{~m}$ luze $\mathrm{H}$-rantz, nondik beste galeria txikiago batzuk jaiotzen diren; bestea, 43 m luze HE-rantz. Azken horrek goranzko desnibela du ibilbide guztian.

Barnean, bizi izandako lekutik urruti eta banakatuta, labar-artearen hainbat multzo daude, puntu eta marra gorriz egindakoak (13. ird.).

Haitzuloaren garapena, sarreratik gaurkoz ezagutzen dugun leku sakoneraino, 85 m-koa da.

\section{3.- INGURU GEOGRAFIKO ETA ARKEOLOGIKOA}

\subsection{Inguru geografikoa}

Haitzuloa Deba ibaiaren behe-arroan zabaltzen da, gaur egungo ibaitik eta Debaren herrigunetik bi kilometro- ra, bertan ibaiak marrazten duen meandroetariko baten gainean. Eremu horretako morfologia, Izarraitz mendigunearen I-IE mendi-hegalean kokatuta, malkartsua eta pikoa da; erliebea tontor-segida bat da eta $\vee$ itxurako haranek aldapa handiak dituzte (EDESO, 1985, 1990).

Praileaitz I haitzulotik $65 \mathrm{~m}$ desnibeleko malda handi bat ikusten da, aurrean bertan, ibairaino jaisten dena (ibaiak hemen errio izaera du). Kontrako ibaiertzean eta haitzuloaren ipar-mendebaldean Etxezabalko Haitza mendia kokatzen da, gutxi gorabehera $130 \mathrm{~m}$ garai eta itxura konikoduna; iparralderantz, Iruroingo Haitza mendia dago, 113 m altu; eta ipar-ekialdean, Istiña muinoa, 115 m garai. Haitzuloaren ahotik ekialdean-hego-ekialdean, metro gutxira agertzen da Ermittia mendia (itxura konikoduna); gaur egun, Bilbo-Behobia autopistak zeharkatzen du tunel baten bidez. Garaiera txikiko mendi eta muino horien segida Deba ibaitik nahiko hurre dago, eta menditxo horien artean meandro batzuk eratuz itsasoratzen da gaur egungo Debako herrigunean. Mendi horietatik ez oso urruti beste handiago batzuk daude, adibidez Arno (618 m)

Gaur egun inguruko landaredia honako hauek osatzen dute: Quercus familiakoak, hau da, artadi kantauriarra, harizti azidofiloa eta harizti-baso misto atlantikoa; haltzadi kantauriarra, ur gezatako lasterren ondoan; Pinus radiataren landaketa ugari eta zenbait belardi. 


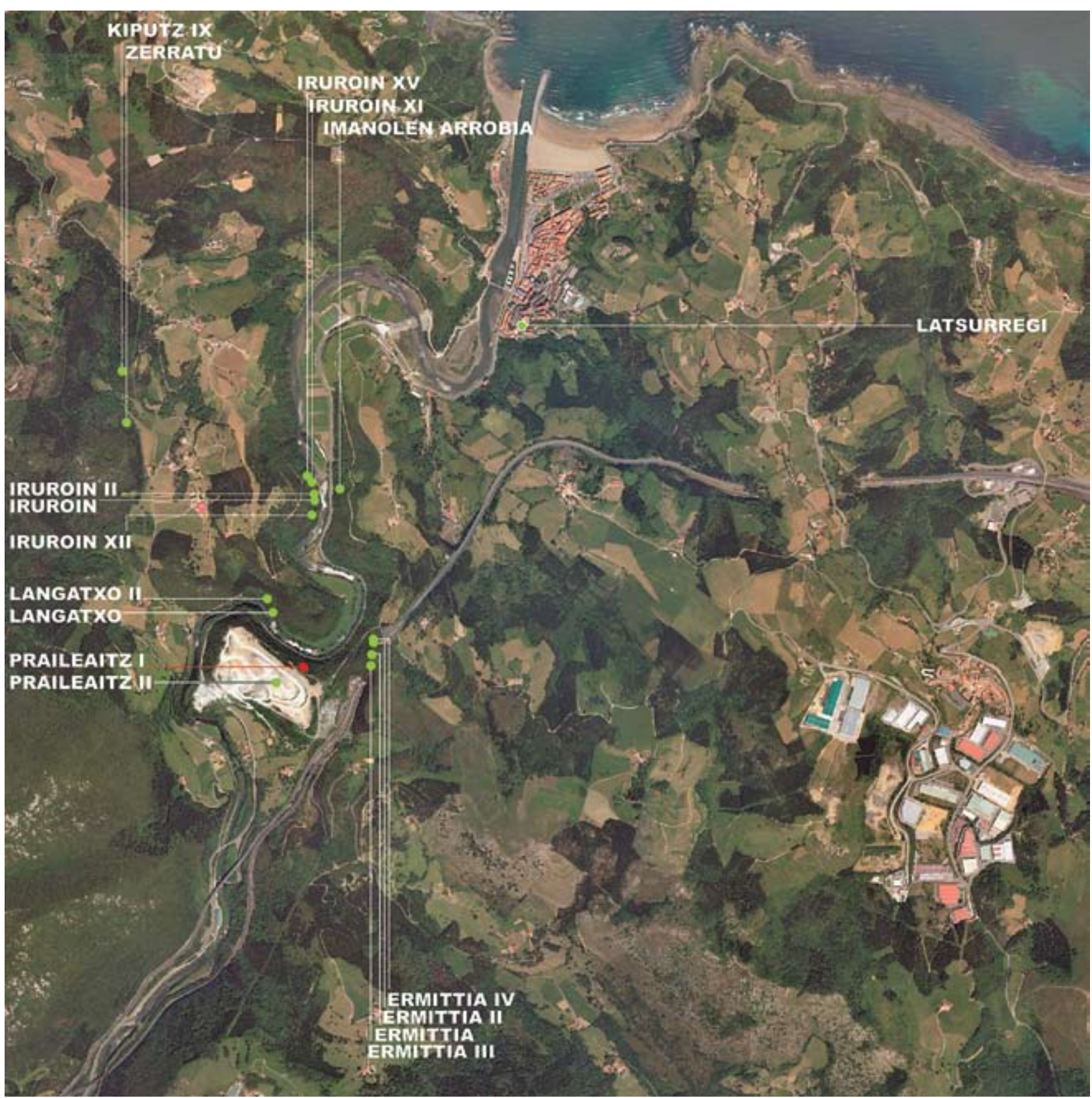

14. ird. Paleolito Aroko aztarnategia duten zenbait haitzuloen kokapena Debabarrenan (Gipuzkoako Foru Aldundia -1:5000-, T. Carrascal). Location of some caves with Paleolitic sites in Debabarrena (Provincial Council of Gipuzkoa -1:5000-, T. Carrascal).

Eremuko lurzoru karetsuak erraztu egiten du haitzuloak eta babeslekuak egotea, handiagoak edo txikiagoak, eta horietako asko Historiaurreko hainbat unetan okupatuak, batez ere Paleolito garaian.

Praileaitz I haitzuloa zabaltzen den mendia erabat hondatuta dago dago, bertan dagoen agregakinen harrobi itzel batek ia dena suntsitu duelako. Beste kobazulo batzuk dinamitatu zituzten duela hainbat urte, Praileaitz II esaterako. Mendi horretatik, egun, zerrenda periferiko estu bat baino ez da geratzen, eta oraindik suntsiketak segitzen du ez baitira Amenabar Taldeko Zeleta S.L. ha- rrobiko erauzketa-lanak gelditu, Eusko Jaurlaritzaren uztailaren 17ko 120/2007 dekretuaren onespenarekin².

\subsection{Inguru arkeologikoa}

Euskal Herriko Goi Paleolitoko aztarnategiak ez dira uniformeki barreiatzen, lurraldearen geologiak eta erlie-

2 120/2007 DEKRETUA, uztailaren 17koa, Debako (Gipuzkoa)
Praileaitz I Haitzuloa, Monumentu izendapenaz, Kultura Ondare
gisa deklaratzen dena. Euskal Herriko Agintaritzaren Aldizkaria gisa deklaratzen dena. Euska
143, 2007ko uztailaren 26koa. 
beak (garaiera, etab.) asko baldintzatzen duelako haitzuloen agerpena eta haien biziegokitasuna. Argi dago aire zabaleko aztarnategiak ugariagoak direla, baina horiek aurkitzeko dauden zailtasunak handiak dira. Bestalde, ur azpian egongo liratekeenak (egun suntsituta daudenak) ere gehitu beharko lirateke. Ezagutzen ditugun haitzuloetako bizilekuak egungo itsasertzaren inguruko orban kareharritsuetan sakabanatuta agertzen dira multzoak sortuz: Karrantza inguruan, Arenaza, Urdaibai, Anboto ingurua, Lea, Artibai, Deba Goiena, Deba Barrena, Urola Behea, Aralar, Landarbaso, etab.

Praileaitz I haitzuloa Deba Barreneko multzoa osatzen duen kobetako bat da. Inguruan kokatzen dira berarekin harreman zuzena (noski, toki bakoitzeko kronologiaren arabera) izango zuten Ermittia, Iruroin, Langatxo, Agarre, Aizkoltxo, Urtiaga, etab. Mendebalderantz, hurbileneko aztarnategiak Lekeitioko Lumentxa eta Santa Catalina ditugu, Bolinkoba -Abadiño-, Atxuri -Mañaria-, Abittaga -Amoroto- eta Arlanpe -Lemoa-; Urdaibai inguruan, berriz, Atxeta -Forua-, Santimamiñe -Kortezubieta Antoliña -Arteaga-. Ekialderantz, berriz, hor ditugu Urola arroko Amalda, Erralla eta Ekain, eta Gipuzkoako ipar-ekialdean Landabarsoko haitzetan Aitzbitarte III et IV, Torre, eta Pirinioen iparraldean Isturitze, Azkonzilo, Arancou, Harregi, etab.

Orain dela ia mende batetik hona, Historiaurreko lanetan eta ikerketetan ibili diren miatzaileek zein arkeologoek arreta handia jarri diete Debabarreneko eta aldameneko tokietako eremu karetsuei.

Jardun arkeologiko horiek informazio bikaina eman dute geografia-eremu pribilegiatu honetako historiaurreko okupazioez (MUJIKA, PEÑALVER, SAN JOSE, 2009), bai aztarnategi zehatz batzuei buruz (14. ird.) (ALTUNA et al. 1982 eta 1995; BARANDIARAN, 1967, 1972; GONZÁLEZ SAINZ, 1989; MUJIKA, 1983, 1991; MUJIKA, PEÑALVER, 2012; SÁENZ DE BURUAGA et al., 2009; UTRILLA, 1990), bai maila orokorragori dagokionez.

Jarraian aztarnategi katalogatuen hautaketa labur bat jasoko dugu. Horietan guztietan esku-hartze arkeologikoak egin dira, eta, gure ustez, esanguratsuenak dira. dira:

Debako udalerrian nabarmentzeko haitzuloak hauek

\subsubsection{Astigarraga}

Haitzuloa Goltzibar haranean dago itsas mailatik 436 m gora. Azkoitiko Munibe taldeko kideek aurkitu zuten 1967an, eta azalean fauna aztarnak bildu zituzten. 2005etik aurrera indusketa arkeologikoaren beste fase bat hasi zuen J.A. Mujikak aipatutako taldeko kideen laguntza zuela (ARRUABARRENA et al., 2006, 2007, 2008 eta 2014). 2009an labar-artearen multzo bat aurkitu zen (ALBERDI et al. , 2010): binakako marra gorriak eta orban beltz bat (litekeena da zaldi bat izatea). Kobazuloan gizakia sarri bizi izan da Behe-Paeolitoaren bukaeratik, modu iragankor batean izan bada ere, eta hainbat aztarna iso- latu eman ditu Behe- eta Goi-Paleolitokoak, Antzinako Epipaleolitokoak eta Brontze Arokoak.

\subsubsection{Ekain}

Haitzuloa Ekain mendiaren ekialdeko hegalean zabaltzen da (15. ird.), Goltzibar eta Beliosoro errekek bat egiten duten lekutik metro gutxira -hortik aurrera errekari Sastarrain deitzen zaio-, Urolako ibarrean, itsas mailatik 90 m gora. Kobazuloa aurkitu zenean, ekialderanzko orientazioa zuela, 2,30 zabal eta 1,20 altu zen, eta 2x3 $\mathrm{m}$-ko atari batetik aldameneko galeria bat ateratzen zen 13 m-ko garapen eta, gutxi gorabehera, 2 m-ko zabalerakoa. Esparru horretatik, non arkeologia-metakina dagoen, hainbat galeria eta gela ateratzen dira, eta leku horietan horma-irudi ugari aurkitu ziren.

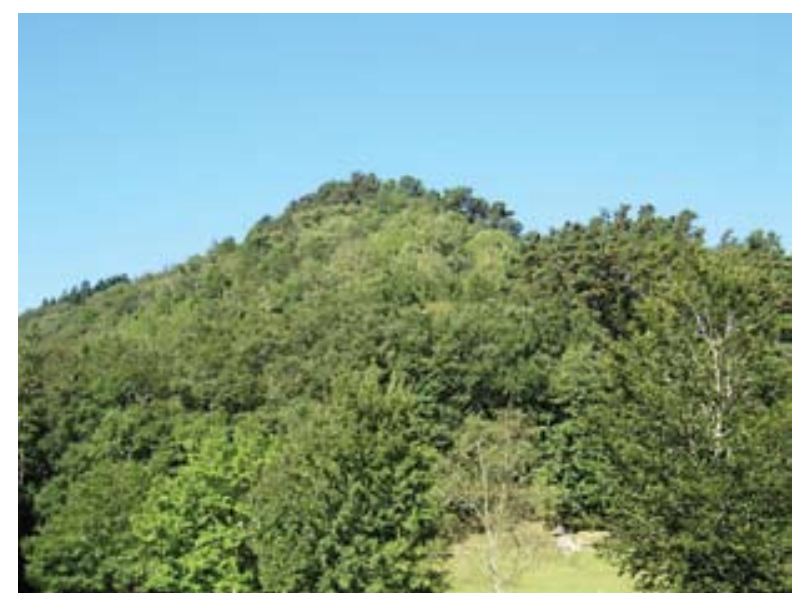

15. ird. Ekain mendia, bertan izen bereko haitzuloa dago. / Mount Ekain, where Ekain cave is located.

Azpeitiko Antxieta taldeko A. Albizurik eta R. Rezabalek aurkitu zuten haitzuloa 1969an, eta urte berean hasi ziren indusketa-lanak J.M. Barandiaran eta J. Altunaren zuzendaritzapean; 1971 eta 1972an jarraitu zuten, eta 1973 eta 1975 artean J. Altunak segitu zuen (ALTUNA, MERINO, 1984). Gerora, zuzendari berak 2008 eta 2011 artean berriz ekin zion indusketari (ALTUNA, 2009, 2010, 2011, 2012). Lan horiek guztiek ekarri dute bertan bizi izandako gizakien beste hainbat aztarna identifikatzea."

Haitzuloaren kultura-segida aldi hauei dagokie: Aurignac-Perigord, Behe Madeleine kantauriarra, Erdi Madeleine -azken kanpainetan identifikatua eta lehenagoko VIc mailaren parekoa-, Goi-Azken Madeleine, Azil eta Azil Sauveterroide, baita berrerabilpen puntualen bat hilobi gisa ere Neolito amaieran.

Horma-irudiak bost multzotan agertzen dira (FANO, RIVERO, GARATE, 2012), guztira 70 hasierako inbentarioaren arabera, baina kopuru hau handitu egin da gutxienez beste bisonte-irudi bat identifikatu duelako ( $C$. GONZÁLEZ SAINZ et al, 1999). Irudi gehienak margotuta daude, baina gutxi batzuk grabatuta, eta irudiren batek 
elkartzen ditu bi teknikak. Zaldia nagusitzen da irudikatutako animalia-espezieen artean.

\subsubsection{Ermittia}

Haitzuloa izen bereko mendian zabaltzen da, itsas mailatik 130 m gora. Sarrera, ipar-mendebalderantz, 2 m zabal eta 2,20 m garai da (16. ird.). Horren ondoren atari bat zabaltzen da, eta barrurantz jarraitzen du beheranzko galeria baten bidez harik eta gela handi batean bukatu arte, nondik hiru galeria ateratzen diren; horietako bat kanporako irteera du.

J.M. Barandianek aurkitu zuen 1924an, eta hark berak indusi zuen T. Aranzadirekin batera 1924 eta 1926 artean (ARANZADI, BARANDIARAN, EGUREN, 1928). Azalean aztarna arkeologiko batzuk aurkitu ziren 80. hamarkadan. Gela handiko jalkinaren zati handi bat desagertu egin zen Bilbo-Behobia autopistak mendia zeharkatzeko egindako lanengatik, baita klandestinoek sarrerako lekukoan egindako arpilatzeagatik ere.

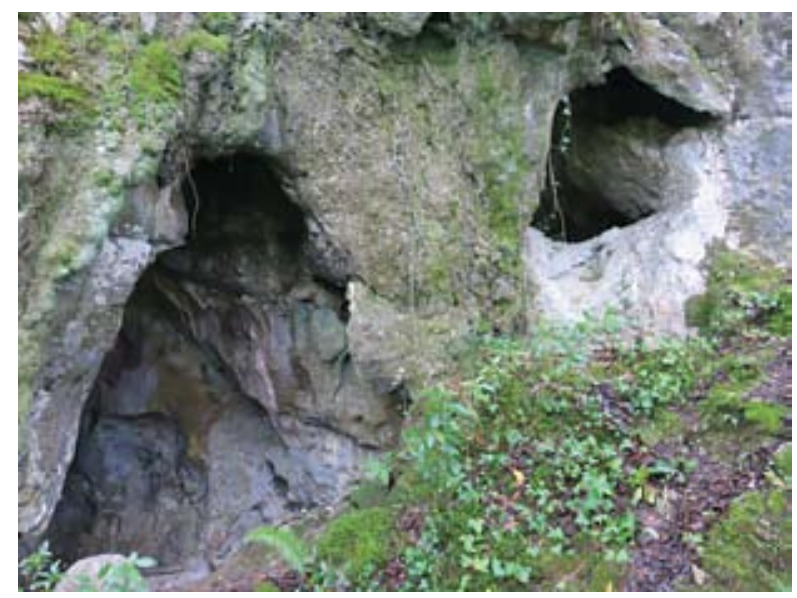

16. ird. Ermittia haitzuloa. / Ermittia cave.

Aztarnategiko kultura-segida hauxe da: balizko Gravette, Solutre, Erdi eta Goi-Azken Madeleine, Azil eta zeramika duten mailak (BARANDIARAN, UTRILLA, 1975; ESPARZA, MUJIKA, 1999).

\subsubsection{Praileaitz II}

Haitzuloa Praileaitz mendiaren mendebaldeko hegalean zegoen, itsas mailatik $120 \mathrm{~m}$ gora. Egun suntsituta dago Sasiolako harrobiaren jarduna dela-eta. Kobazulo txikiak gela erdizirkular bat zeukan 17 m²-koa eta 1 m-ko altuerakoa, eta tamaina txikiko bigarren gela batean bukatzen zen. Haitzuloaren ahoa, mendebalderantz orientatua, 4,5 m zabal zen, eta bi zatitan zegoen banandua kareharrizko bloke handi batengatik. Juxtu sarreraren parean gutxi gorabehera15 m²-ko eremu berdindu bat zegoen.

Kobazulo hau Azkoitiko Munibe Taldeko kideek aurkitu zuten 1986an, eta E. Uribarrik osorik indusi zuen 1988 eta 1989 artean (URIBARRI, 1988, 1989). Indusketa arkeologikoak hainbat maila eman ditu: Aurignac, Gravette eta Azil aldiak, baita material zeramikoei eta metalikoei lotutako beste maila batzuk ere, azken hauek oraindik ikerketa fase batean daudenak.

\subsubsection{Urtiaga}

Haitzuloa Salbatore mendiaren hego-mendebaldeko hegalaren oinarrian zabaltzen da, itsas mailatik $160 \mathrm{~m}$ gora. Ahoa hego-mendebalderantz dago, eta $3 \mathrm{~m}$ zabal eta 3,50 m garai da. Aurkitu zen unean, kobazuloak 10 m-ko pasatzeko moduko garapena zuen eta bi eta hiru $\mathrm{m}$-ren arteko zabalera, baina, indusi eta gero, posible da 60 m-an zehar jarraitzea (17. ird.).

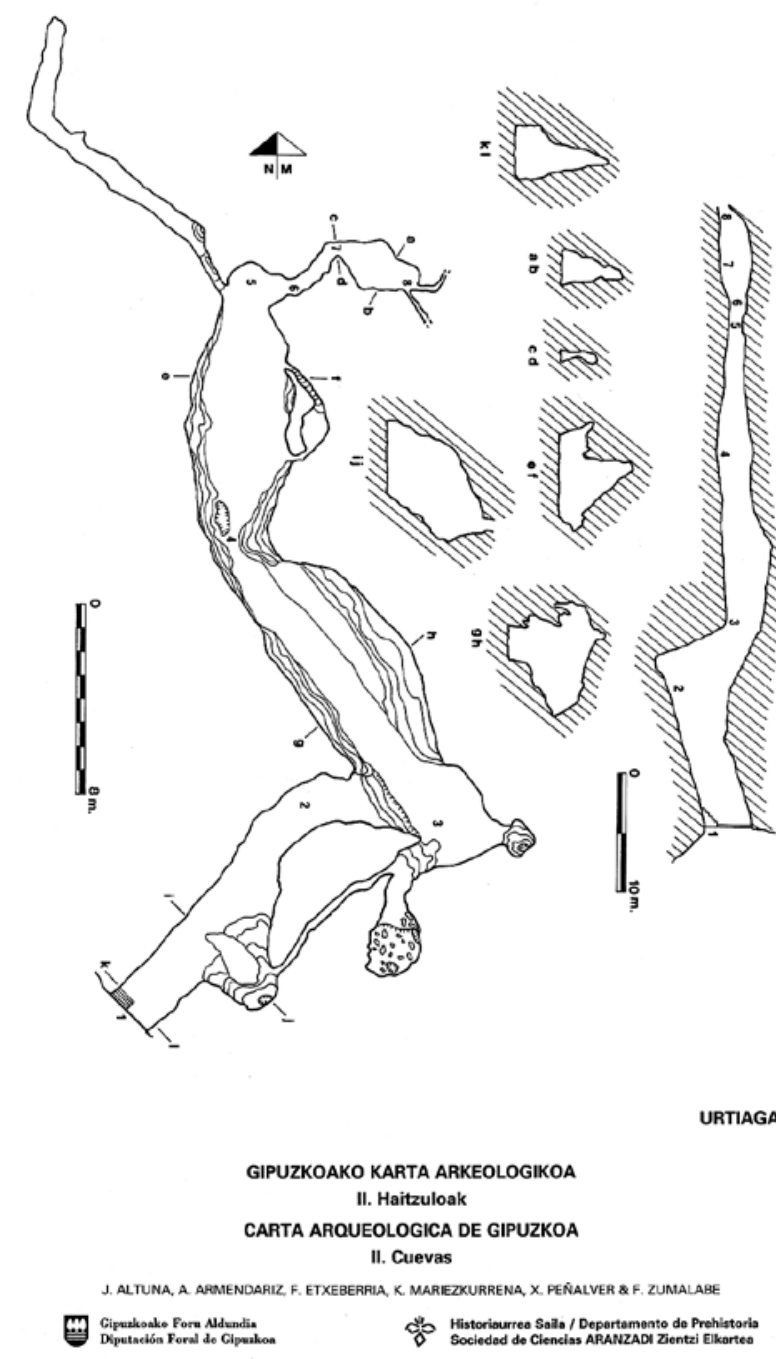

17. ird. Urtiaga haitzuloaren plano topografikoa (Gipuzkoako Karta Arkeologikoa, ALTUNA et al., 1995). / Topographic plan of Urtiaga cave (Gipuzkoako Karta Arkeologikoa, ALTUNA et al., 1995). 
18. ird. Deba ibaiaren ondoan dauden Langatxo eta Iruroingo haitzuloen ingurunea. Sorroundings of the caves of Langatxo and Iruroin, near the Deba river.

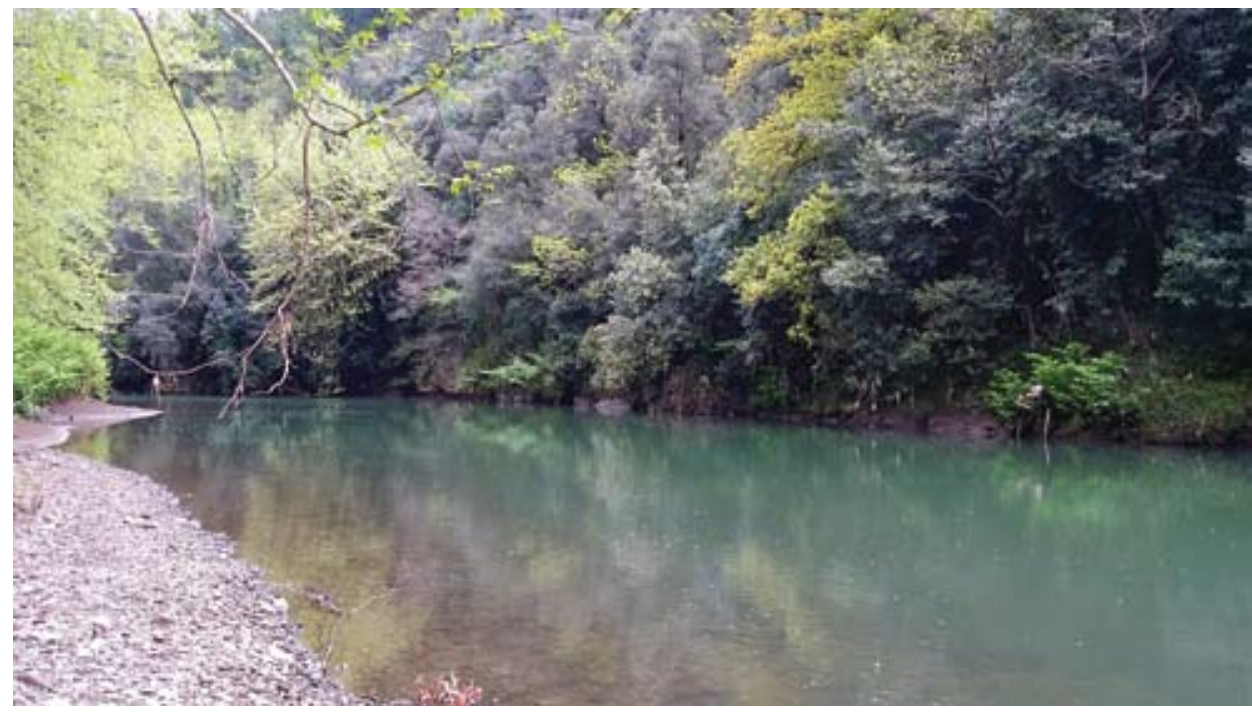

J.M. Barandiaranek aurkitu zuen 1928an, eta T. Aranzadirekin batera indusi zuen 1928. eta 1936. urteen artean; lanari berriro ekin zioten 1954, 1955 eta 1959an (ARANZADI, BARANDIARAN, 1948; BARANDIARAN, 1947, 1948, 1960; BARANDIARAN, ELOSEGUI, 1955; BARANDIARAN et al., 1955; BARANDIARAN, SONNEVILLE BORDES, 1964, GONZÁLEZ SAINZ, 1984). J.A. Mujikak berrartu zuen esku-hartzea 1986 eta 1988 artean (MUJIKA, 1986), kobazuloaren barreneko lekukoaren ebaketa bizituz estratigrafia egiaztatzeko, sedimentologia- eta palinologia-laginak biltzeko, baita C14aren bidez okupazioak datatzeko ere. Antzemandako mailak hauexek dira: Goi-Azken Solutre; Behe, Erdi eta Goi-Azken Madeleine; Azil, eta material zeramikoa dutenak (okupazio neolitiko puntual bat eta hiletaberrerabilpen bat Kalkolitoan eta Brontze Aroan) (MUJIKA 2011; MUJIKA, PEÑALVER, 2012).

Mendaroko udal-mugartean honako kobazuloak nabarmendu behar dira:

\subsubsection{Aizkoltxo}

Haitzuloa izen bereko muino baten goialdean dago, Kurutz Gain industria-poligonoan, itsas mailatik 30 m gora. Sarrera, hego-mendebalderantz, 2 m zabal eta 1,20 garai da; barruan, 3x4 m-ko gela txiki bat zabaltzen da; horren ondoren, bidegurutze bat dago, zeinaren galeriak $10 \mathrm{~m}-\mathrm{ko}$ altuerarainoko malda bat jarraitzen duten. Bere oinarrian $4 \times 3 \mathrm{~m}$-ko gela bat eta $7 \mathrm{~m}$-ko garapena duen galeria bat daude. J.M. Barandiarani egozten zaio aurkikuntza 1927an, hura izan baitzen jendaurrean ezagutzera eman zuena kata bat egin ostean, non emaitza positiboak izan zituen. Halere, benetako aurkitzailea Lorenzo Sierra izan zen, 1909ko abuztuaren 17an, Monako Printzea Santanderrera iritsi aurretik, zeinak jakinarazi zuen Sociedad de Historia Natural sailean (MADARIAGA DE LA CAMPA, 2005). 2005etik aurrera, ezkutuko batzuk gelako ezkerreko aldean ibili zirenez geroztik, J.M. Mujika, Azkoitiko Munibe Taldeko kideen laguntzarekin, ebaketaren zuzenketa bat egin zuen eta kanpoan $2 \mathrm{~m}^{2} \mathrm{ko}$ zundaketa bat, babesleku antzeko batean (litekeena da kobazuloaren beste sarrera bat izatea) (CASTAÑOS et al., 2009, MUJIKA, 2006-2007-2009-2011-2014). Lan horietan hainbat maila identifikatu dira: Azken Madeleine, Azil eta, gutxienez, hileta-berrerabilpen bat Kalkolitoan.

\subsubsection{Aldatxarren}

Haitzuloa Santa Krutz mendiaren hegalean dago, itsas mailatik 138 m gora. Ahoa 1,25 m garai eta 4,50 m zabal da. Barruan, espazioa ia zirkularra da, 5,80 eta 5,20 m-ko ardatzak dituela; kanpoan -kobazuloaren aurrealdearen atzerapenagatik- bada 5×3,50 m-ko plataforma angeluzuzen bat, eta litekeena da han gizakia bizi izana.

Azkoitiko Munibe Taldeko kideek aurkitu zuten 1983an, baita arkeologia-metakina ere. A. Saenz de Buruagak indusi zuen 2005etik aurrera hiru kanpainan zehar (SAENZ DE BURUAGA, 2006, 2007, 2008). Okupaziotik Gravette maila nabarmentzen da, baina badira zantzu Aurignac batzuk.

Azkenik, Mutrikuko haitzulo garrantzitsuenak hauexek dira:

\subsubsection{Iruroin}

Haitzuloa Deba ibaiaren ezkerraldean dago, ibaitik 30 bat metro gora (18. ird.). Bi sarbide ditu altuera desberdinetara eta batetik bestera $6 \mathrm{~m}$ daude. Horren ondoren, 9x3 m-ko atari bat dago; handik katazulo bat ateratzen da mendebalderantz eta galeria bat ipar-mendebalderantz; lehena, jalkinez guztiz beteta.

Azkoitiko Munibe Taldeko kideek aurkitu zuten 1973an (bi kata egin zituzten). 1979 eta 1980an hustuketa lanak egin zituzten barruko katazulora iristeko, eta orduan bildu ziren hainbat material arkeologiko. 1994 eta 1999 ar- 
tean F. Zumalabek indusi zuen (ZUMALABE, 1994, 1995, 1996, 1998, 1999), eta maila hauei buruzko informazioa jaso zen: Azken Madeleine eta Paleolito ondorengoko kronologia duten hilobiratze batzuk.

\subsubsection{Kiputz IX}

Mutrikuko udal-mugartean dagoen leize bat da, itsas mailatik 119 m gora, sakonera 5 m-koa du eta ahoaren diametroa gutxi gorabehera 2 m-koa. Azkoitiko Munibe Taldeko kideek aurkitu zuten 2002an, eta P. Castañosek indusi zuen 2004 eta 2007 artean (CASTAÑOS, 2005, 2006, 2007, 2008). Lanari dagokionez, azalez azal beheraino jaisteaz gain, geruza estalagmitiko bat desagerrarazi behar izan zen oinarri naturaleraino iristeko. Aztarnategi honek izugarrizko balioa du, batez ere arlo paleontologikoan, bi arrazoirengatik: arrazoi nagusia, hamar bat espezietako makrougaztunen 14.000 hezur baino gehiago bildu dira, nabarmentzekoak oreina, bisontea eta elur-oreina; bestea, noizbehinkako gizakien agerpena Goi Paleolitoan leizean eroritako animaliak aprobetxatzeko.

\subsubsection{Langatxo}

Haitzuloa Deba ibaiaren ezkerraldean dago, ibilgutik metro gutxira, itsas mailatik $5 \mathrm{~m}$ gora (18. ird.). Sarrera, hegoalderantz, 2 m zabal eta 1,50 m garai da. Babesleku txiki baten ondoren, tamaina urriko atari bat zabaltzen da, eta bertatik bi galeria ateratzen dira. Kobazuloa guztira, $50 \mathrm{~m}$ luze da.

Azkoitiko Munibe Taldeko kideek aurkitu zuten 1981ean, eta han kata bat egin zuten. F. Zumalabek indusi zuen 1990 eta 1993 artean, eta bi maila agertu ziren: Azken Madeleine eta Kalkolitoa (ZUMALABE, 1990, 1991, 1992, 1993).

\subsubsection{Zerratu}

Kobazuloa Arno mendiaren ekialdeko mendi saihetsean dago, itsas mailatik $113 \mathrm{~m}$ gora, eta tamaina txikikoa da: 1,50 m sakon, $1 \mathrm{~m}$ zabal eta 1,50 garai. Munibe taldeko M. Sasietak eta J.M. Arruabarrenak aurkitu zuten, eta 2001ean kata bat egin zuten. A. Saenz de Buruagak indusi zuen 2002 eta 2004 artean. Lan horiei esker bildu den informazioak esaten digu ehiza-atsedenlekua izan zela Erdi Paleolitoko hainbat alditan (SAENZ DE BURUAGA, 2003, 2004, 2005).

\section{4.- PRAILEAITZ I HAITZULOAREN IKERKETEN HISTORIA}

Praileaitz I haitzuloa M. Sasietak, J.M. Arruabarrenak eta Azkoitiko Munibe Taldeko beste kide batzuek aurkitu zuten 1983an (19. ird.). Orduan, azalean material batzuk bildu eta atondoaren iparraldean kata bat egin zuten, hormari itsatsia. Era berean, lubaki-kata ${ }^{3}$ bat egin zuten

\footnotetext{
${ }^{3}$ Lubaki-kata hau atondoaren barnean antzeman zen IV.III azpimaila industean, eta $12 \mathrm{H}$ koadroari eragiten dio, ia oso-osorik, eta $10 \mathrm{H}$ koadroari ekialdeko erdia.
}

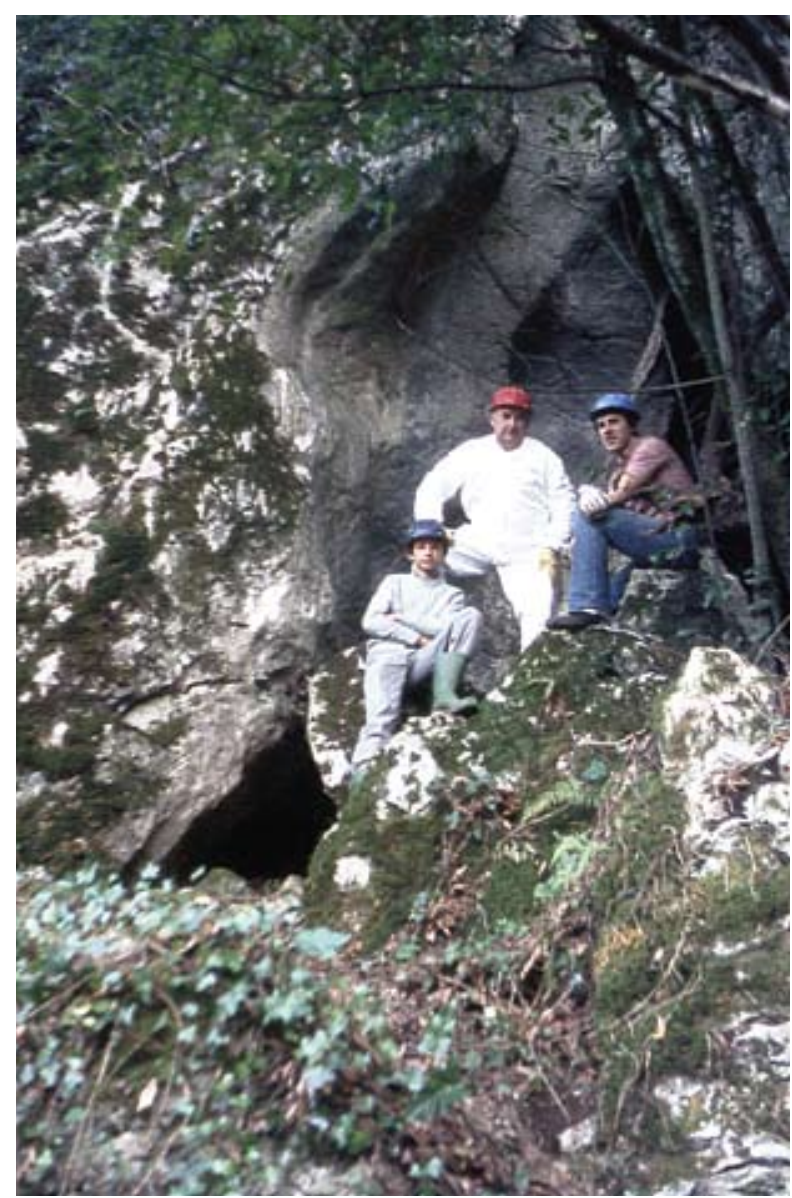

19. ird. Praileaitz I haitzuloaren aurkitzaileak (Munibe Taldea). / Discoverers of Praileaitz I cave (Munibe Taldea).

kobazuloaren kanpotik barrura, sarreraren zati bat estaltzen zuten bloke erorietatik beheko kota batera.

1986an Donostiako Aranzadi Zientzia Elkarteko Historiaurreko Arkeologia saileko hainbat kidek beste kata bat egin zuten. Kata horretan suharrizko bi ijelki eta printza bat aurkitu zituzten, baita zenbait fauna-aztarna ere.

Indusketa arkeologikoa 2000ko ekainean hasi zen, eta, bi urte pasatxoko etenaldi baten ondoren, gaur arte jarraitu du X. Peñalverren zuzendaritzapean (22. eta 23. ird.). Kanpaina horietan, administrazioak bertako jarduera hainbat modutan hartu du: hasieratik 2005. urtera arte, larrialdiko indusketa arkeologikoa izan zen, zeren eta haitzuloa suntsitu egin behar baitzuten lanak bukatuta; 2006tik 2009 arte, ordea, ikerketa-jarduera bihurtu zen. Azken kategoria hori gaur egun indarrean dago, 2012an landa-lanak berriro hasi zirenetik (PEÑALVER, 2000-2002 -2003-2004-2005-2006-2007-2008a-2008b-2009a $-2009 b-2013-2014 a, 2014 b)$.

2000. urtean hasi zen indusketa, ekainean eta uztailean zehar, eta lan egin zen haitzuloaren ahoaren ondoko kanpoko plataforman, baita atondoaren eremu txiki batean ere. Jarduketa horretan, sarreran zegoen kareharrizko bloke erori handiaren zati bat kendu zen. Kanpaina 
20. ird. Lydia Zapata, egur-ikatz begetalen laginak jasotzen. / Lydia Zapata, picking up samples of charcoal.

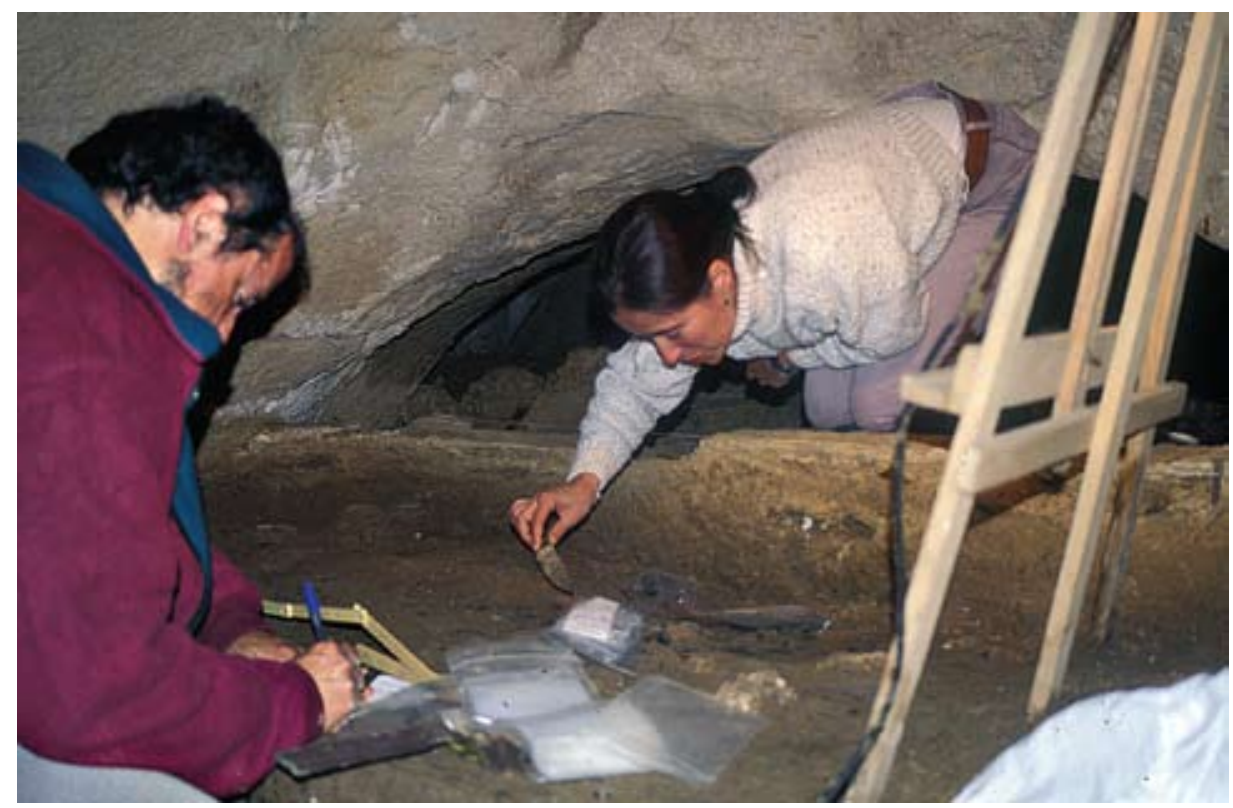

horren emaitza izan ziren kanpoko plataforman aurkitutako Paleolito garaiko aztarnak eta, atarian indusitako eremuan, okupazioko lehenengo testigantzak.

2001. urtean, apirilean eta maiatzean indusi zen, haitzuloaren atondoan, eta Madeleine aldiko lehenengo berezko aztarnak dokumentatu ziren. Gainera, atondo barnean sei zintzilikario aurkitu ziren, hiru harrizkoak eta beste hiru, hortzetan eginak (PEÑALVER, MUJIKA, 2003, 2005a eta 2005b).

2002an martxoan, apirilean eta maiatzean lan egin zen, baita ekaineko egun batzuetan ere, bai atondoan, bai atondotik lehen barne-gelara doan pasabidean, bai ipar-mendebaldeko galerian. Beste harrizko zintzilikario bat aurkitu zen kanpaina horretan.

2003ko apirilaren eta uztailaren artean, biak barne, lanek jarraitu zuten atondoan, ipar-mendebaldeko galerian eta atondotik lehen barne-gelara doan pasabidean, non azken leku horretan agertu zen sutondo epipaleolito handi bat (20 eta 21. ird.). Halaber, kontserbaziorako haitzulotik atera ziren aulkia eta bere altxagarri- edo ziri-harria, aldez aurretik atarian aurkitutakoak, eta haitzuloaren sarreran zegoen hainbat tonatako bloke handia osorik kendu zen.

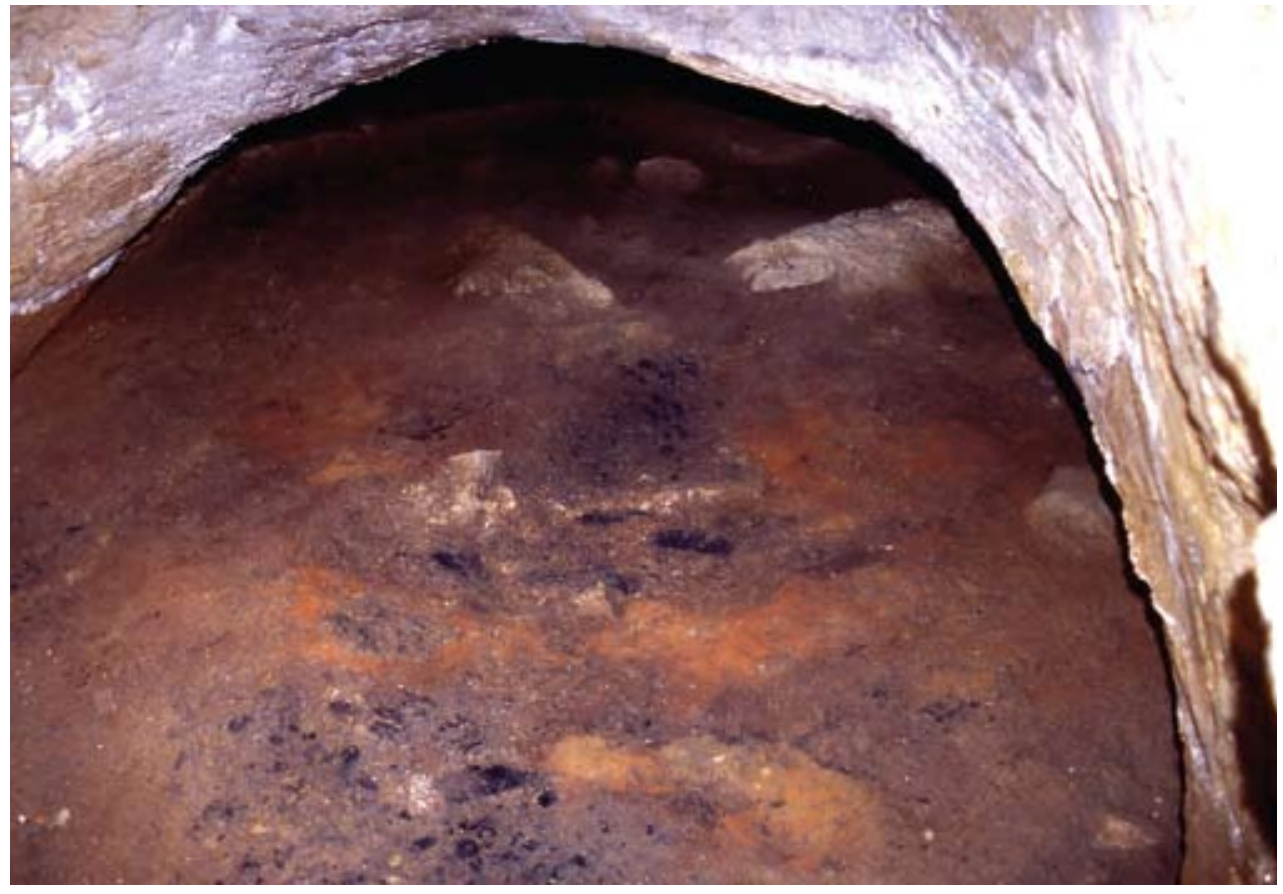

21. ird. Atondo eta lehen barne-gelaren pasabidean dagoen sutondo epipaleolitokoa. / Epipaleolithic hearth that was located on the area leading from the vestibule to the first inner room. 


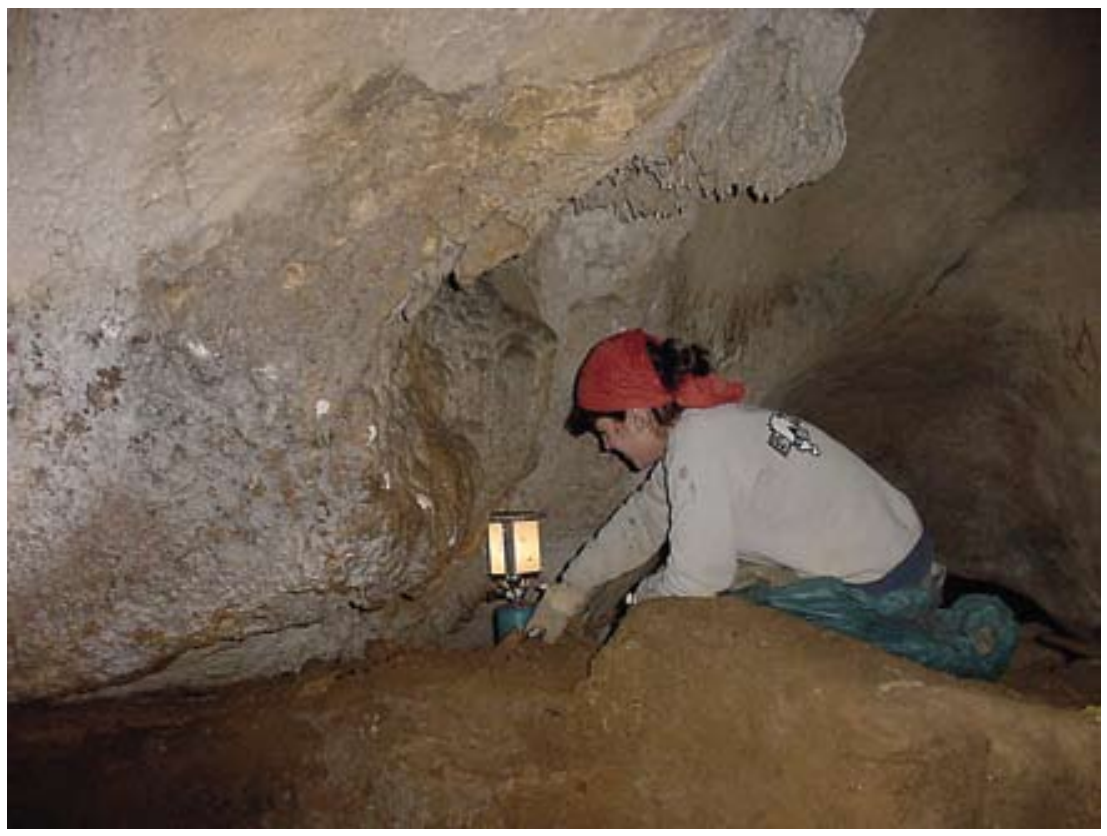

22. ird. Indusketa-lanen ikuspegia hasierako uneetan. / Sight of the excavation at the beginning of the works.

2004ko kanpaina maiatzaren eta uztailaren artean eta irailaren eta azaroaren lehenengo egunen artean izan zen. Atondotik lehen barne-gelara doan pasabidean lan egin zen, baita lehen barne-gela horretan, non beste sutondo epipaleolito bat agertu zen. Kanpaina luze horretan berrehun itsas maskor baino gehiago aurkitu ziren, pasabidearen maila epipaleolitoan. Halaber, lehen barne-gelan, errenkan hamaika harrizko zintzilikario aurkitu ziren, baita beste bost ere gelan barreiatuta, denak Behe Madeleinekoak. Bi kata egin ziren: lehena, lehen barnegelan; bigarrena, ipar-mendebaldeko galerian. Biek jalkin emankorrak dituzte Behe Madeleineko mailen azpian.

2005eko uztailean bi lekutan egin zen lan: lehen barne-gelaren Madeleine mailan eta atondotik lehen barnegelara doan pasabidean. Lehen gelan, eta aurreko urtean
23. ird. Lehen barnegelaren indusketa-lanak. / Excavation works at the first inner room.

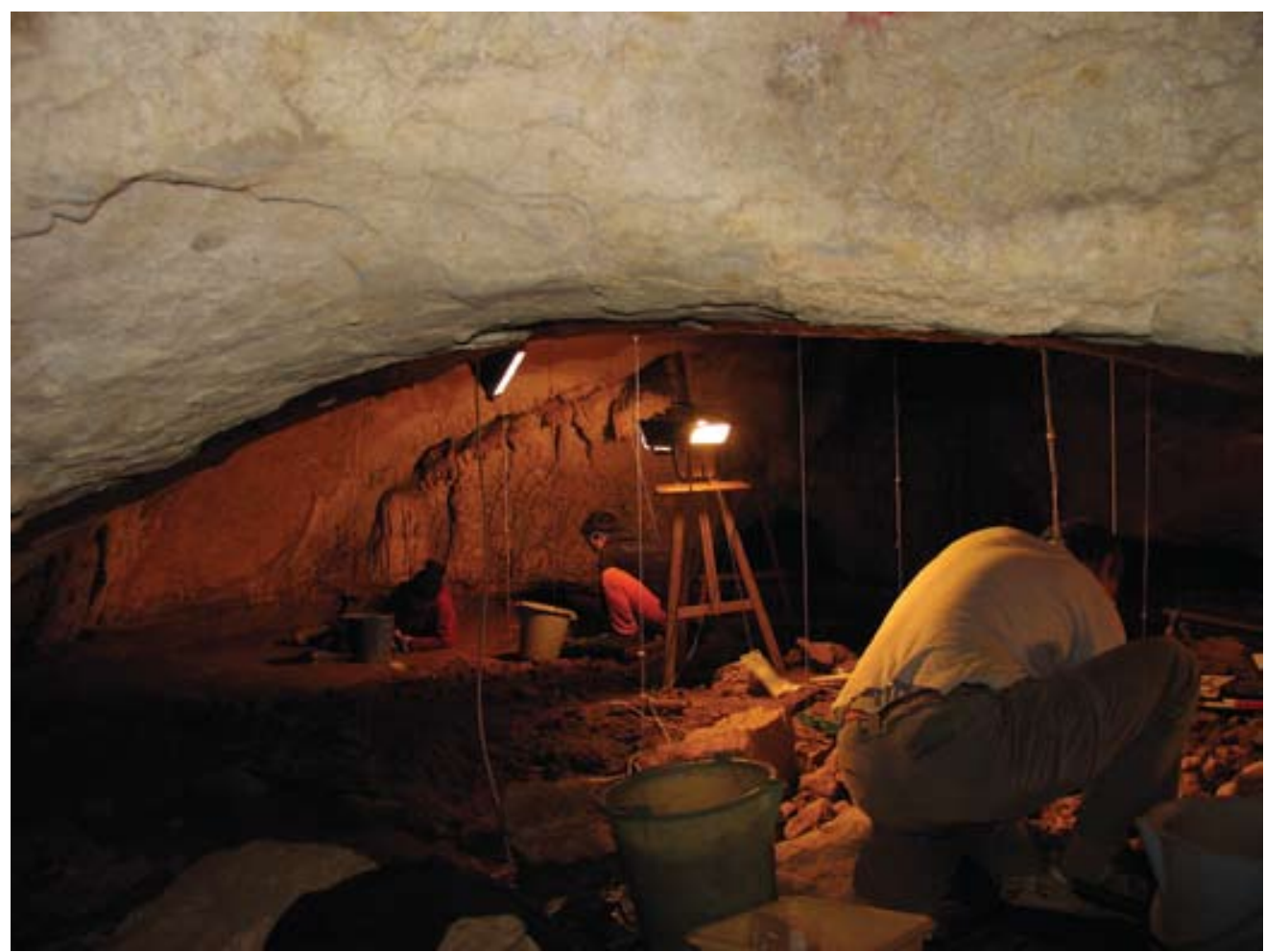




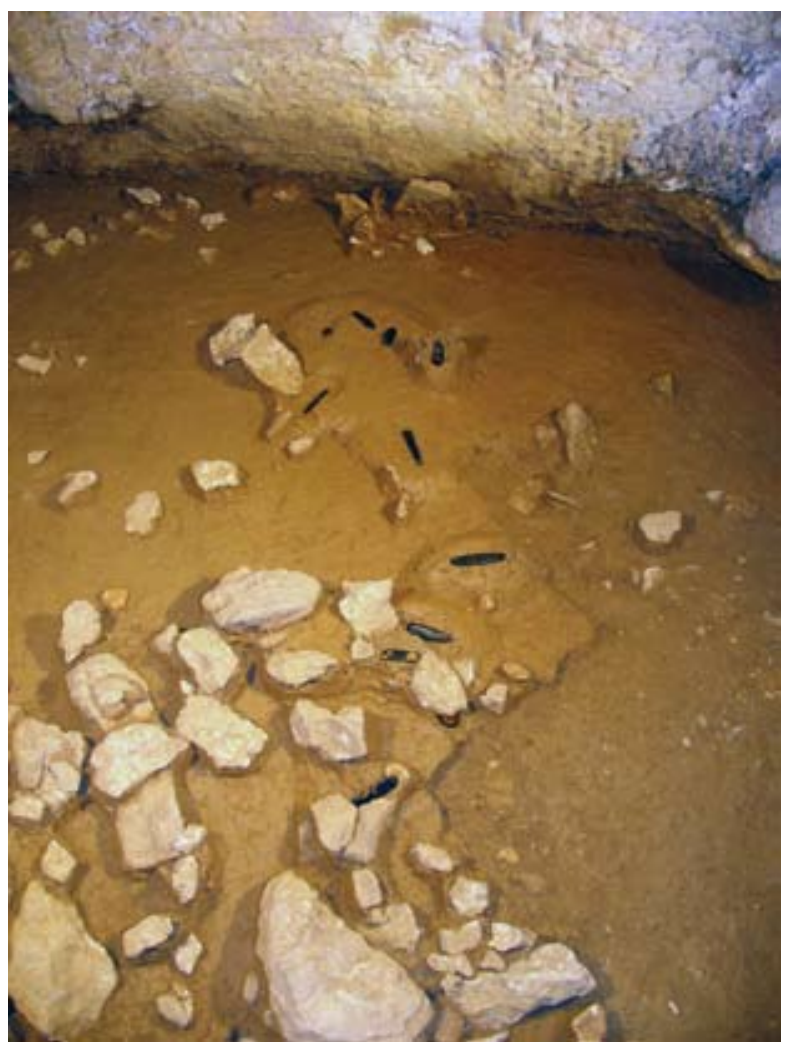

24. ird. Zintzilikarioen multzoa lehen barne-gelan. / Group of pendants at the first inner room.

hamaika zintzilikarioak aurkitu ziren eremuan (24. ird.), hiru gehiago topatu ziren, baita beste hiru ere gela horretako beste leku batzuetan (PEÑALVER, MUJIKA 2007 -2008; PEÑALVER, SAN JOSE, MUJIKA, 2006).

2006ko ekainaren eta abuztuaren artean, baita urrian ere, lehen barne-gelan jarraitu zen lanean, eta Solutre mailaraino iritsi zen. Era berean, beste bi lekutan hasi ziren lanak: bigarren barne-gelan, eta ipar-mendebaldetik mendebalderantz doan katazuloan. Kanpaina horretan,

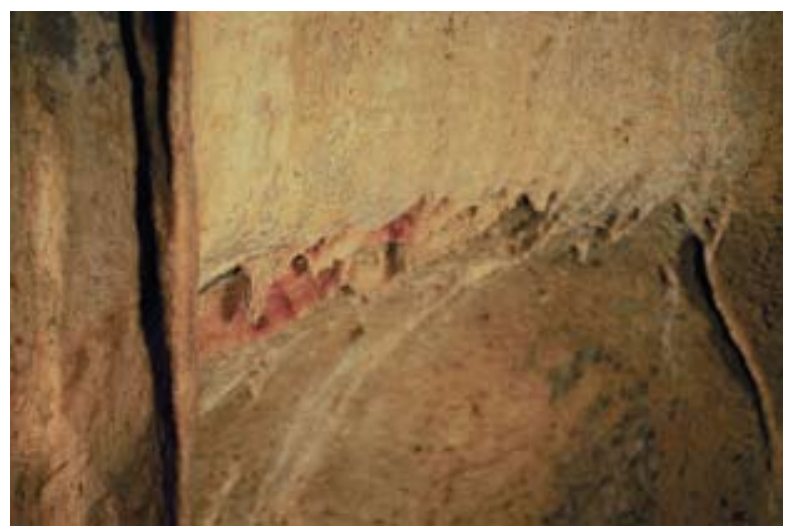

25. ird. Praileaitz I haitzuloaren labarretako margo baten xehetasuna. / Detail of one parietal painting at Praileaitz I cave. labar-pinturak aurkitu ziren haitzuloaren leku sakon batean (25. ird.).

2007ko kanpainan, matxoaren eta ekainaren artean, bigarren barne-gelan egin zen lan.

2008ko kanpainan, ekainean, uztailean eta irailaren eta abenduaren artean indusi zen. Aurreko urtean bezala, bigarren barne-gelan jardun zen.

2009. urtean gela berean segitu zen urtarrilean zehar. Une horretan eten ziren landa-lanak, eta 2012a arte ez zitzaien berriro ekin. Hala ere, 2009. urtetik aurrerako kanpainen emaitzak ez dira jasotzen monografia honetan.

Talde bat izan da bederatzi urte hauetan zehar landalanak egiten eta beste bi urte eta erdi aztarnategiaren gainean lanean. Talde hori X. Peñalverrek zuzendu du, eta, Monografia hau egiteko, diziplinarteko taldea koordinatu dute aipatutako zuzendariak, S. San Josek eta J.A. Mujikak. Indusketan parte hartu dutenak (26. ird.), une desberdinetan, hauexek izan dira: M. Agirre, Tx. Costas, M. Eskudero, H. Fernandez, J. Fuldain, Ma . J. Iriarte, J. Iriondo, Mª. Izquierdo, F. Lopez, R. Madrazo, A. Olazabal, N. Sarasola, J. Tapia, M. Telletxea, E. Uribarri eta V. Uribarri. Beste laguntzaile batzuk: I. Arnaez, B. Arregi, M. Ceberio eta P. Ruiz de Angulo. Era berean, prospekzioetan eta indusketa arkeologikoaren prestakuntza-lanetan honako hauek parte hartu dute: M. Sasieta, J.M. Arruabarrena, T. Agirre-Mauleon, A. Izagirre eta S. Lasa.

Kanpaina hauei aurre egiteko, Gipuzkoako Foru Aldundiaren Kultura Sailak eman ditu diru-laguntzak. 2000 eta 2005 artean, Zeleta enpresak parte hartu zuen finantziazioan, eta, 2006an, Aldundiarekin batera Debako udalak eta Euskadiko Kutxak lagundu zuten. Horrez gain, material arkeologikoak katalogatzeko Eusko Jaurlaritzako Kultura Sailaren laguntza jaso da.

\section{5.- ESKERRONAK}

J. Mujika-Alustizak Euskal Sistema Unibertsitarioaren IT-622-13 Ikerketa-taldearen barnean egin du lan hau.

\section{6.- BIBLIOGRAFIA}

ALBERDI, J., ARRUABARRENA, J., MUJIKA, J. A., SASIETA, M. 2010 Astigarraga haitzuloa. Arkeoikuska 09, 343-345.

ALTUNA, J,

2009-10-11-12 Ekain haitzuloa (Deba). I, II, III, IV kanpainak (2. fasea). Arkeoikuska 08, 09, 10, 11: 358-365, 345-348, 346-348, 336-338.

ALTUNA, J., ARMENDARIZ, A., ETXEBERRIA, F., MARIEZKKURRENA, K., PEÑALVER, X., ZUMALABE, F. J.

1995 Gipuzkoa. Karta Arkeologikoa. II. Haitzuloak. Munibe. Suplemento Antropologia-Arkeologia 10.

ALTUNA, J., MARIEZKURRENA, K., ARMENDARIZ, A., BARRIO, L. DEL, UGALDE, T., PEÑALVER, J.

1982 Carta Arqueológica de Guipúzcoa. Munibe 34, 5-242. 


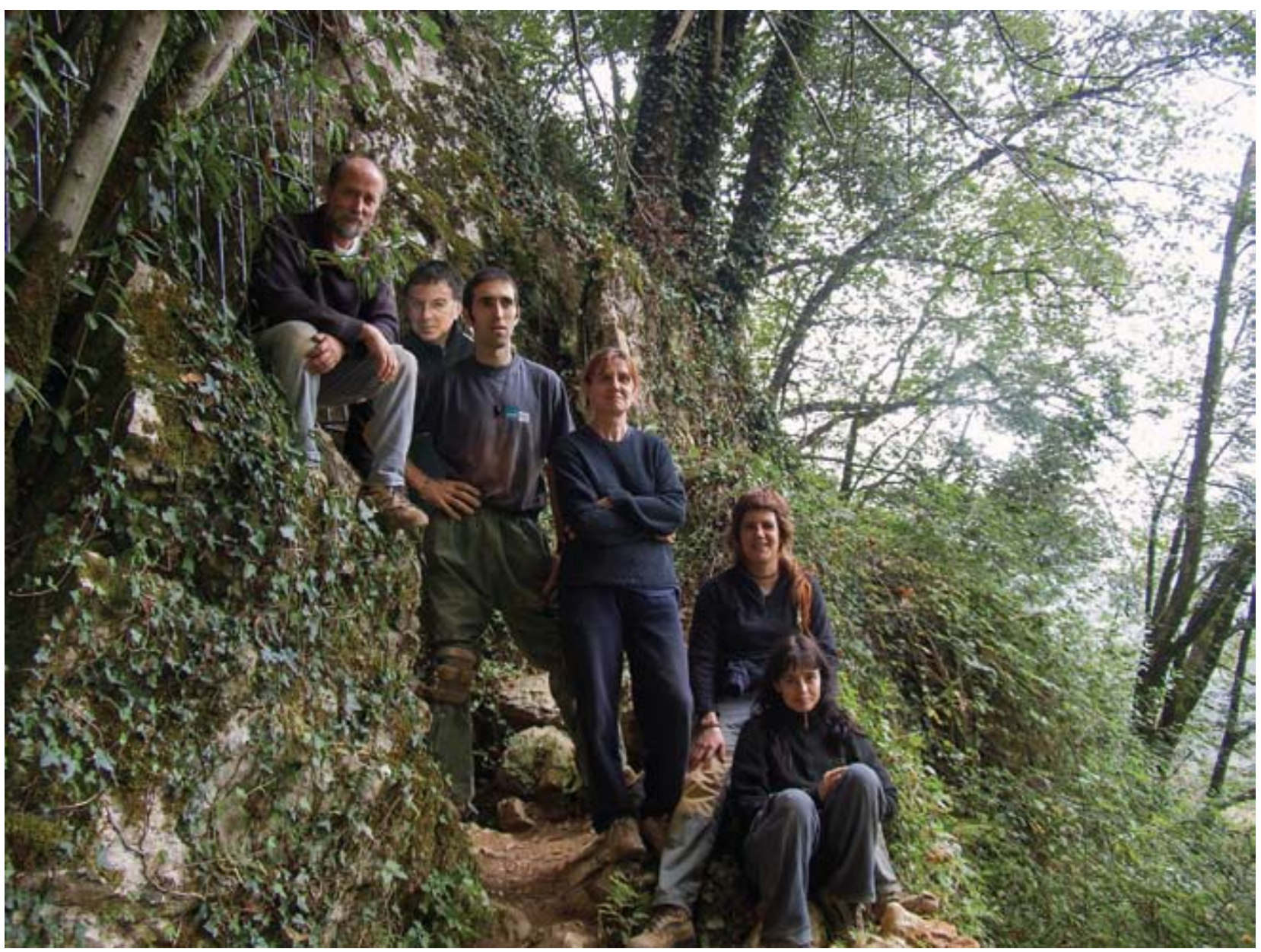

26. ird. Praileaitz I haitzuloko ohiko indusketa-taldea. / Usual working group at Praileaitz I cave.

ALTUNA, J., MERINO, J. M.

1984 El yacimiento prehistórico de la cueva de Ekain (Deba, Gipuzkoa). Sociedad de Estudios Vascos. Serie B 1, 1-351.

ARANZADI, T. DE, BARANDIARAN, J. M. DE

1978 Exploración de la cueva de Urtiaga (en Itziar-Guipúzcoa), en BARANDIARAN, J. M. Obras Completas XII. 237-282. Bilbao.

1976 Exploraciones prehistóricas en Guipúzcoa los años 192427. Cavernas de Ermittia (Sasiola), Arbil (Lastur) y Olatzazpi, dolmen de Basagain (Murumendi) y caverna de Irurixo Nergara), en BARANDIARAN, J. M. Obras Completas X. 163-261. Bilbao.

BARANDIARAN, J. M. DE, ELÓSEGUI, J.

1955 Exploración de la cueva de Urtiaga (en Itziar, Guipúzcoa), in BARANDIARAN, J. M. Obras Completas Xll. 285-294. 1978. Bilbao.

ARRUABARRENA, J., MUJIKA, J.A., SASIETA, M.

2006-2007-2008 Astigarraga haitzuloa. Arkeoikuska 05, 06, 07: 129-131, 179-181, 336-339.
ARRUABARRENA, J., ALBERDI, J., MUJIIKA, J. A., SASIETA, M. 2014 Astigarraga haitzuloa. Arkeoikuska 13, 290-291.

BARANDIARAN, I.

1967 El Paleomesolitico del Pirineo Occidental; bases para una sistematización tipológica del instrumental óseo paleolítico. Monografías Arqueológicas III. Zaragoza.

1973 Arte mueble del Paleolítico Cantábrico. Monografías Arqueológicas XIV. Zaragoza.

BARANDIARAN, I., UTRILLA, P.

1975 Sobre el Magdaleniense de Ermittia (Guipúzcoa). Sautuola I. Publicaciones del Patronato de Cuevas Prehistóricas de Santander 14, 21-47.

BARANDIARAN, J. M. DE

1947 Exploración de la cueva de Urtiaga (En Itziar Guipuzcoa). Gernika-Eusko Jakintza 1, 113-128, 265-271, 437-456 y 679-696.

1948 Exploración de la cueva de Urtiaga. Gernika-Eusko Jakintza 2, 285-307.

1960 Exploración de la cueva de Urtiaga (X|a y X $\|^{\mathrm{a}}$ campañas). Munibe 12, 3-18. 
1978 Exploración de la cueva de Urtiaga (X|a X|l ${ }^{a}$ campañas), en BARANDIARAN, J.M. Obras Completas XII, 297-312. Bilbao.

BARANDIARAN, J.M. DE, ELÓSEGUI, J.

1955 Exploración de la cueva de Urtiaga (10 campaña). Munibe 7, 69-80.

1978 Exploración de la cueva de Urtiaga (en Itziar-Guipúzcoa), en BARANDIARAN, J.M. Obras Completas XII, 285-294. Bilbao.

BARANDIARAN, J.M. DE, SONNEVILLE BORDES, D.

1964 Magdalénien et Azilien d'Urtiaga (Guipúzcoa). Etude statistique. Miscelánea Homenaje al Abate Breuil I, 163-171. Barcelona.

CASTAÑOS, P

2005-2006-2007-2008 Kiputz IX haitzuloa (Mutriku). Arkeoikuska 04-05-06-07, 141-143, 136-138, 190-193, 376-378.

CASTAÑOS, P., HEDEOS, J.M., MUJIKA, J. A., MURELAGA, X.

2009 Aizkoltxo haitzuloa (Mendaro). Arkeoikuska 08, 399-402.

EDESO, J. M.

1985 El relieve del País Vasco. Cuadernos de Sección. Historia-Geografia 5, 19-31.

1990 Geomorfología fluvial y litoral del extremo oriental de Gipuzkoa (País Vasco). Tesis doctoral. Universidad de Zaragoza.

ESPARZA, X., MUJIKA, J. A

1999 Reflexiones en torno a la estratigrafía de Ermittia (Deva, Guipúzcoa). Congreso Nacional de Arqueología XXIV (Cartagena, 1997), 61-69. Cartagena.

FANO, M.A., RIVERO, O., GARATE, D.

2012 Cueva de Ekain. Revisión del arte paleolítico. I campaña. Arkeoikuska 11, 339-341.

GONZALEZ ECHEGARAY, J., GONZALEZ SAINZ, C.

1994 Conjuntos rupestres paleolíticos de la Cornisa Cantábrica. Complutum 5, 21-43.

GONZÁLEZ SAINZ, C.

1984 Sobre la plaqueta grabada magdaleniense de la cueva de Urtiaga (Guipúzcoa). Munibe Antropología y Arqueología $36,11-17$.

1989 El Magdaleniense Superior-Final de la región cantábrica. Tantin, Universidad de Cantabria. Santander.

GONZALEZ SAINZ, C., CACHO TOCA, R., ALTUNA, J.

1999 Una nueva representación de bisonte en la cueva de Ekain (País Vasco). Munibe Antropologia-Arkeologia 51, 153-159.

LARRAÑAGA, $X$.

1991 Deba haraneko historiaurrea. Ikerlan Saila. Bergarako Udala. Bergara.
MADARIAGA DE LA CAMPA, B.

2005 Recordando a Hermilio Alcalde del Río, en LASHERAS, J.A. \& GONZALEZ ECHEGARAY. El significado del Arte Paleolítico. 53-63. Ministerio de Cultura y Museo de Altamira.

MUGICA, J. A.

1983 La industria de hueso en la Prehistoria de Guipúzcoa. Munibe 35, 451-631.

MUJIKA, J.A.

1986 Urtiaga haitzuloa. I. kanpaina. Arkeoikuska 86, 36.

1991 La industria ósea del Paleolítico Superior y Epipaleolítico del Pirineo occidental. Universidad de Deusto. Billbao.

2006-2007-2009-2011-2014 Aizkoltxo haitzuloa (Mendaro). Arkeoikuska 05, 06, 08, 10, 13: 456-459; 187-190; 399402; 377; 317.

2011 Urtiagako haiztuloa (Deba). La cueva de Urtiaga (Deba), in ARRIZABALAGA, A., IRIARTE, M.J. Ehiztari-biltzaileak Gipuzkoako Historiaurean - Los grupos de cazadoresrecolectoresben la Prehistoria de Gipuzkoa. 197-202. Arkeologia 0.1. Gipuzkoako Foru Aldundia. Donostia.

MUJIKA, J.A., PEÑALVER, $X$.

2012 La ocupación de la cuenca del Deba (Gipuzkoa) durante el Magdaleniense inferior. Actas de la Primera Mesa Redonda. El Paleolítico Superior Cantábrico. San Román de Candamo. 97-112. Universidad de Cantabria. Santander.

MUJIKA, J.A., PEÑALVER, X., SAN JOSE, S.

2009 Consideraciones sobre la puesta en valor de los yacimientos en cueva del Paleolítico Superior en el bajo valle del Deba (Gipuzkoa). Medio siglo de arqueología en el Cantábrico Oriental y su Entorno: actas del Congreso Internacional. 1061-1070. Gasteiz.

PEÑALVER, $X$

2001-2002-2003-2004-2005-2006-2007-2008a-2009a-20132014a Praileaitz I haitzuloa (Deba). I, II, III, IV, V, VI, VII, VIII, IX, X, XI. kanpaina. Arkeoikuska 00, 01, 02, 03, 04, 05, 06, 07, 08, 12, 13: 84-87, 446-447, 115-116, 115-116, $391,426-427,468-469,340,366,275-277,293-294$.

2008b-09b Praileaitz mendiaren hegalak (Deba). I, II. kanpaina Arkeoikuska 07, 08: 340, 367.

2014b Praileaitz I haitzuloa. La cueva de Praileaitz I (Deba, Gipuzkoa). Gipuzkoako Foru Aldundia. Donostia. (Arkeologia; 4).

PEÑALVER, X., MUJIKA, J.A.

2003 Suelo de ocupación magdaleniense en la cueva de Praile Aitz I (Deba, Gipuzkoa): evidencias de arte mobiliar. Veleia 20, 157-181.

2005a Praile Aitz I (Deba, Gipuzkoa): evidencias arqueológicas y organización espacial en un suelo Magdaleniense, en $\mathrm{BICHO}, \mathrm{N}$. (ed.). O Paleolítico. Actas do N Congreso de Arqueología Peninsular (Faro 14 a 19 de septiembre de 2004). 143-156. Universidade do Algarve. Faro. (Promontoria Monográfica; 02). 
2005b La cuestión de las azagayas de base hendida magdalenienses en la cornisa cantábrica. Veleia 22, 9-20.

2007-2008 ¿Actividad cotidiana o práctica ritual?. Agrupación de 14 colgantes líticos del Magdaleniense Inferior en la cueva de Praileaitz I (Deba, Gipuzkoa). Veleia 24-25, 209-228.

PEÑALVER, X., SAN JOSE, S.

2008 La grotte de Praileaitz I (Deba, Gipuzkoa, Euskal HerriaPays Basque) et la défense du patrimoine dans le Pays Basque. Préhistoire du Sud-Ouest 16, 143-150.

2009 La cueva de Praileaitz (Deba): un caso paradigmático de los déficits en la conservación del patrimonio vasco. Medio siglo de arqueología en el Cantábrico Oriental y su Entorno: actas del Congreso Internacional. 1049-1060. Gasteiz.

PEÑALVER, X., SAN JOSE, S., MUJIKA, J.A.

2006 Praileaitz I haitzuloko (Deba) Madeleine aldiko zintzilikarioak. Gipuzkoako Foru Aldundia. Donostia. (Bertan; 22).

SÁENZ DE BURUAGA, A.

2003-2004-2005 Zerratu haitzuloa (Mutriku). Arkeoikuska 02, 03, 04: 137-146, 137-145, 144-153.

2006-2007-2008 Aldatxarren haitzuloa (Mendaro). I, II, III. kanpaina. Arkeoikuska 05, 06, 07: 115-125, 168-175, 367-374.
SÁENZ DE BURUAGA, A., CASTAÑOS, P., DIEZ FERNÁNDEZLOMANA, J.C., ROMÁN GONZÁLEZ MORALES, J., LÓPEZ QUINTANA, J.C., MUJIKA ALUSTIZA, J.A.

2009 El Paleolítico en el Cantábrico Oriental y su entorno inmediato: un somero balance de su presente desde la reflexión de algunos de sus sujetos y claves de investigación. Medio siglo de arqueología en el Cantábrico Oriental y su Entorno: actas del Congreso Internacional. 9-72. Gasteiz.

URIBARRI, E.

1988-1989 Praile Aitz II haitzuloa (Deba, Guipuzkoa). I, II. kanpaina. Arkeoikuska 88, 89: 103-105, 164-16.

UTRILLA, P.

1990 La llamada "facies del País Vasco" del magdaleniense inferior cantábrico. Apuntes estadísticos. Munibe Antropologia-Arkeologia 42, 41-54

\section{ZUMALABE, F.}

1990-1991-1992-1993 Langatxo haitzuloa (Mutriku). I, II, III, IV. kanpaina. Arkeoikuska 90, 91, 92, 93: 80-82, 100-102, 194-197, 168-172.

1994-1995-1996-1998-1999 Iruroin haitzuloa (Mutriku). I, II, III, IV, V. kanpaina. Arkeoikuska 94, 95, 96, 98, 99: 154-158, 166-168, 126-127, 134-135, 98-101. 
